\title{
Panthers and Forests in South Florida: an Ecological Perspective
}

\author{
$\underline{\text { E. Jane Comiskey }}^{1}, \underline{\text { Oron L. Bass, Jr. }}^{2}, \underline{\text { Louis J. Gross }}^{1}$, Roy T. McBride $^{3}$, and $\underline{\text { Rene Salinas }}^{1}$
}

ABSTRACT. The endangered Florida panther (Puma concolor coryi) survives in an area of pronounced habitat diversity in southern Florida, occupying extensive home ranges that encompass a mosaic of habitats. Twenty-one years of daytime monitoring via radiotelemetry have provided substantial but incomplete information about panther ecology, mainly because this method fails to capture movement and habitat use between dusk and dawn, when panthers are most active. Broad characterizations of panther habitat suitability have nonetheless been derived from telemetry-based habitat selection studies, focusing narrowly on forests where daytime resting sites are often located. The resulting forest-centered view of panthers attributed their restricted distribution and absence of population growth in the mid-1990s to a scarcity of unfragmented forest for expansion. However, the panther population has doubled since the beginning of genetic restoration in 1995, increasing five-fold in public areas described as unsuitable based on forest criteria. Although the forest-centered view no longer explains panther distribution, it continues to shape management decisions and habitat conservation policies. The assumptions and limitations of this view therefore merit critical examination. We analyze the role of forests in the ecology of the Florida panther. To address the absence of nighttime telemetry data, we use innovative telemetry mapping techniques and incorporate information from field observations indicating habitat use during active hours (e.g., tracks, scats, urine markers, and kill sites). We consider daytime telemetry data in the context of panther home ranges and breeding units. We analyze home range size in relation to the amount of forest within each range, concluding that percent forest cover is a poor predictor of size. We apply fractal analysis techniques to characterize the relative density of forest cover associated with daytime locations and interpret the results in terms of spatial landscape patterns, highlighting the limitations of daytime telemetry data for characterizing overall habitat use. We conclude that the forest-centered view of panther habitat selection is based on an uncritical evaluation of telemetry data collected prior to the recent population expansion and on the unsupported assumption that day bed habitats are representative of nighttime habitat use. We find that numerous factors contribute to habitat suitability and population density and distribution, and that $P$. concolor in Florida, as elsewhere in their range, are habitat generalists, exploiting the broad spectrum of available habitats for hunting, resting, mating, travel, denning, and dispersal. Whereas panthers readily use forested habitat with understory and prey, we find no support for the view that only the forested land within a habitat mosaic is potential panther habitat, or for the contention that only forested habitats are used by panthers within existing home ranges. We suggest a more ecologically consistent management and recovery paradigm based on maintaining the integrity of the system of overlapping home ranges that characterizes panther social structure and satisfies breeding requirements. Such a paradigm focuses on the requirements for reproductive success of a small population in a changing environment.

\section{INTRODUCTION}

The Florida panther (Puma concolor coryi), one of the most publicized endangered animals in the United States, has become a symbol for vanishing wildness. The state mammal of Florida, the panther has been featured on a postage stamp and is the subject of a special Florida vehicle license plate, with sales designated to support panther recovery efforts. The ongoing processes of planning for the restoration of the Everglades ecosystem (http://www.sfrestore.org/) and the development of a landscape conservation strategy for panthers (http://www.verobeach.fws.gov/msrp) involve numerous public policy issues affecting panther habitat. An objective evaluation of data on panther activity and habitat use is of critical importance to public policy and land-use decision making in South Florida and to the development of models that may influence these processes.

Extensive and ongoing radiotelemetry monitoring and

${ }^{1}$ University of Tennessee; ${ }^{2}$ Everglades National Park; ${ }^{3}$ Livestock Protection Company 
field studies of panthers have been conducted in Florida continuously since 1981 , providing a wealth of information about panther biology, behavior, and demographics. The Across Trophic Level System Simulation (ATLSS) modeling group (http://atlss.org), working closely with field biologists, is currently evaluating panther radiotelemetry data. These data are being used to define behavior rules for use in the ATLSS Deer/Panther model, an individual-based spatially explicit model for panthers and white-tailed deer in the Everglades and Big Cypress landscapes (Comiskey et al. 1994, DeAngelis et al. 1998). The predictive capabilities of individual-based models are closely tied to the realism of the decision rules that determine how simulated animals move across the landscape, interact with one another, and respond to their environment. The definition of these rules in turn depends upon the availability and interpretation of empirical observations of behaviors and movement patterns.

Panther home range and habitat use are key behaviors to be considered in formulating appropriate model rules and in planning panther recovery efforts. Monitoring flights are made during the day, when panthers are typically at rest (Land 1994). Although panthers may move about to some extent, especially on cool and cloudy days, daytime locations are not representative of 24-hr activity patterns. Although these data do not reflect panther habitat use during their active hours, they are valuable in establishing the bounds of home-range activity areas, characterizing the dispersal of subadults from natal ranges, and alerting researchers to situations that require management intervention. However, these data have serious limitations for defining panther habitat use, which requires additional knowledge of movements during the hours between dusk and dawn when panthers are most active (Land 1994). Field observations made during thousands of hours of panther tracking operations (McBride 1994) can be used to fill critical data gaps in describing panther habitat use.

Several key quantitative analyses of panther habitat use have been based on the identification of vegetation types associated with daytime telemetry locations. Interpretations of these analyses have focused primarily on forests, in part because panther resting sites are often located in forest understory. Maehr and Cox (1995) used this type of analysis to define the land cover types that panthers in South Florida prefer and avoid. Using fractal analysis techniques, Kerkhoff et al. (2000) found that telemetry locations were consistently associated with locally more extensive forest areas, which led them to conclude that forest cover was a reasonable surrogate for useful panther habitat. Both studies found that the size of panther home ranges was inversely related to the extent of available forest cover, with the added implication that panthers make an effort to incorporate forest resources into their ranges.

The effectiveness of panther habitat protection efforts hinges on how panther habitat is defined, and perceptions of habitat requirements shape other aspects of panther recovery policy as well. Because of the narrow characterization of panther habitat use it presents, the forest-centered view of panthers has important implications for panther recovery. For example, analyses in Maehr and Cox (1995) provide the foundation for the panther-habitat evaluation methodologies proposed for land-use decision making (Maehr and Meegan 2001). Kerkhoff et al. (2000) suggest that a protocol similar to theirs could aid in the estimation of available panther habitat, which they determine to have a lower threshold of $25 \%$ forest cover. The adoption of this view by land-use decision makers could result in the failure to purchase or protect habitats that lack extensive tracts of forest. The assumption made in habitat selection studies based on daytime telemetry, i.e., that resting site locations describe 24-hr habitat use (Maehr 1997a), provides justification for protecting only forest stands, and the surrounding habitat matrix is developed or removed from mitigation formulas. The degree to which forests in South Florida have already been fragmented has also been cited as a reason not to protect land for resident panthers there.

The management of panthers on public land is also guided by the perception of what constitutes suitable habitat. Five healthy female panthers in Everglades National Park (ENP) recently missed two breeding seasons after the death of the lone resident male. Panther management agencies refused requests from the National Park Service (NPS) to translocate a surplus male to the area, in part because of expert opinion (Maehr 1997a, 1997b) that ENP is a population sink for panthers because of fragmented forest cover. The impact of perceptions of panther habitat requirements on recovery policy compels a close examination of both the data record and published analyses.

We describe the emergence of the forest-centered view 
of panthers as an explanation for both the geographical distribution of home ranges and habitat use within home ranges in the mid-1990s, when the population was static and restricted to only a portion of its current occupied range. However, studies that evaluate preexpansion telemetry data continue to be cited as representative of overall panther habitat requirements in South Florida (Maehr and Meegan 2001). The conclusions of these studies provide quantitative support for a view of panthers that is inconsistent with both current field observations in Florida (McBride 2000, 2001) and characterizations of $P$. concolor habitat associations in other parts of their range (Guggisberg 1975, McBride 1976, Dixon 1982, Tinsley 1987). The key but unstated assumptions in these studies were that (1) daytime resting sites are representative of around-the-clock habitat use, (2) the subareas and time periods chosen for analysis are representative of the full set of monitoring data, and (3) habitat effects, rather than reduced fitness caused by inbreeding, were the primary determinants of the shrinking preintrogression panther distribution observed during the period of panther monitoring. We evaluate the soundness of these assumptions.

We present analyses of panther radiotelemetry observations that are based on the full spatial and temporal set of available monitoring data (19812000). This data set includes locations from south of I75 in Big Cypress National Preserve (BCNP) and ENP following the successful introduction of eight Texas panthers. We use these telemetry data to delineate the overlapping network of panther home ranges, which provides the context for evaluation of panther habitat use and relationship to forest cover. Recognizing the limitations associated with data that do not record the habitats used by panthers during the hours when they are active, we use field observations to characterize panther activity during the nighttime hours when most panther activity occurs. We describe the usefulness of telemetry data in delineating home range boundaries and stress the importance of interpreting telemetry data in the context of total home-range use and of the overall breeding range of panthers in South Florida. Based on our results, we examine the assumptions and limitations of the forest-oriented view and evaluate its ability to explain recent changes in panther population size and distribution. We stress the importance of basing recovery strategies on the ecological and biological needs of panthers, and of evaluating these needs in the context of total home-range use within the overall breeding range of panthers in South Florida.

\section{METHODS}

\section{Study area}

Our study area covered $25,000 \mathrm{~km}^{2}$ in South Florida, of which approximately $8000 \mathrm{~km}^{2}$ constitutes the current occupied range of the Florida panther (Fig. 1). This area includes a wide range of natural habitats and human environs found on the Florida peninsula from the vicinity of Lake Okeechobee southward.

Fig. 1. Study area in South Florida encompassing the occupied range of Florida panthers. Vector overlays delineate public areas of South Florida (blue) and approximate boundaries of the panther range (dashed black). Forest pixels are shown in green, agriculture in yellow, pasture/rangeland in orange, urban in gray, all other types in white. BCNP = Big Cypress National Preserve, ENP = Everglades National Park, FSSP $=$ Fakahatchee Strand State Preserve, FPNWR = Florida Panther National Wildlife Refuge, MIR = Miccosukee Indian Reservation, SIR = Big Cypress Seminole Indian Reservation, WCA = Water Conservation Area, and EAA = Everglades Agricultural Area.

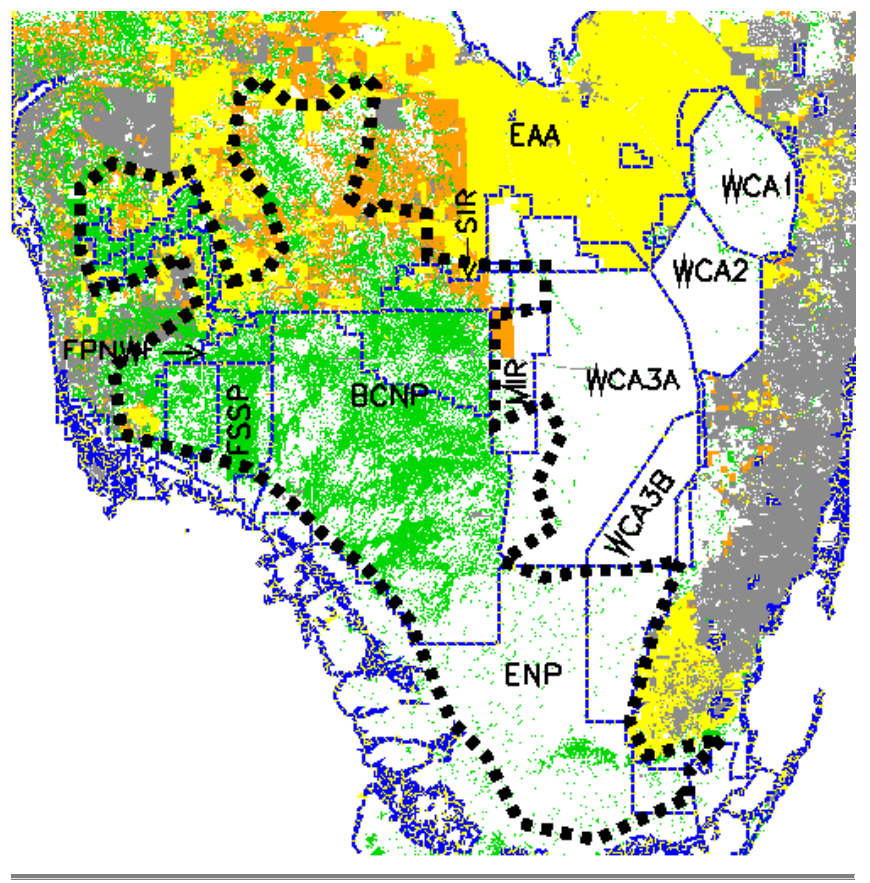

\section{Land classification}

To depict land cover, we used the Florida Gap Analysis Vegetation Map (FGAP) version 6.6 (Pearlstine 2000), which is based on classification of 1993-1994 Landsat TM imagery, with a 30-m pixel resolution. We determined forest cover by grouping all forest classes together and considering all other natural 
and developed classes as nonforest. Although this procedure aggregates forested habitats of varying quality and usefulness for panthers, it is used to provide consistency with the methodology of Kerkhoff et al. (2000) to which the results of this study are compared. FGAP version 6.6 forest types occurring in the study area include 2-Tropical Hardwood Hammock Formation, 3-Semi-deciduous Tropical/Subtropical Swamp Forest, 4-Xeric-Mesic Live Oak, 6-Bay/Gum/Cypress, 8-Cajeput Forest, 13South Florida Slash Pine Forest, 16-Mesic-Hydric Pine Forest, 17-Swamp Forest Swamp Forest, 18-Cypress Forest Cress Forest, 20-Buttonwood Woodland, and 25-South Florida Slash Pine Woodland. Nonforested cover includes a wide range of developed and natural habitats.

\section{Telemetry data}

Biologists from the Florida Fish and Wildlife Conservation Commission (FWC) and the National Park Service (NPS) have been collecting data on panther telemetry locations over the monitoring period from 1981 to the present. As of December 2001, 114 panthers had been monitored, including eight females of the closely related Texas subspecies Puma concolor stanleyana, which were introduced into South Florida in 1995 to enhance the genetic variability of the inbred Florida panthers (Seal 1994, Land and Lacy 2000). Forty-two panthers, 54\% of the known current population (78 panthers), are now radio-collared (McBride 2001).

Telemetry data are collected during daytime flights of fixed-wing aircraft. Except for daily monitoring of panthers in ENP for the period 1986-1991 (Bass 1994), flights are normally conducted three days per week. The radio collar of each monitored panther emits a unique frequency that allows its signal to be distinguished from those of other collared panthers. Each spatial observation is stored as Universal Transverse Mercator grid coordinates at 100-m precision. The date and time are recorded so that patterns of sequential panther movements can be assessed.

It is widely recognized that panthers exhibit distinct daily patterns in activity and habitat use. During nondaylight hours, they roam widely across the mosaic of habitats within their home ranges, with peaks of activity around dusk and dawn (Maehr et al. 1990, Beier et al. 1995). Panthers are typically at rest in dense cover during the day, when monitoring flights are made (Land 1994). The telemetry data, therefore, are not representative of 24-hr activity patterns.

We used these telemetry data in both home range and fractal analyses. The available data included 49,889 observations collected for 102 panthers at 26,182 unique locations through mid-2000. For fractal analysis, only the subset of unique locations was used. A subset of these data covering the period 1981-1993 and including 18,118 locations for 52 panthers was used for comparison to analyses reported by Kerkhoff et al. (2000).

\section{Data sufficiency}

Panther telemetry data have been collected by three different groups from two agencies (the FWC and the NPS). The accuracy of these data is affected by a number of variables, including the equipment used, collection and reporting protocols, and the experience and expertise of operators. Mean error between recorded and actual locations has been estimated to be 204 and $247 \mathrm{~m}$ for the FWC and the NPS, respectively, with $95 \%$ of locations occurring within 489 and 485 m, respectively (Janis 1999, Dees et al. 2001).

We used telemetry locations to define home range boundaries for calculation of home range size and as input to fractal analysis. Because spatial inaccuracies in telemetry locations are small compared to the size of home ranges (means of about 251 and 153 square miles for males and females, respectively), inaccuracies in telemetry measurement should have only a limited effect on estimates of home range size. The threshold of $1.5 \mathrm{yr}$ of residence in a home range for inclusion of an adult panther in the data set assured an adequate number of locations (a minimum of about 230 locations) for defensible estimation of home range size. To the degree that panther activity extends beyond the outer bounds of telemetry observations, home range size will be underestimated. Included figures that show the intensity of use based on daily movement buffers around telemetry points depict possible activity beyond the bounds of telemetry observations.

In fractal analysis, the accuracy of telemetry observations is more important, because analyses are conducted at the pixel level, i.e., the presence of telemetry locations in windows of varying sizes centered on individual forest pixels determines the value of fractal dimensions. The estimated accuracy of 
the average telemetry location is about the width of the smallest window size $(210 \mathrm{~m})$. Therefore, the inaccuracy of telemetry locations could affect the values of fractal dimensions at the smallest window sizes. Because computed fractal dimensions represent averages over plots, some inaccuracy in telemetry measurement can be accommodated. However, if plots have low percent forest cover and also have relatively few telemetry locations ( 14 plots had fewer than 90 locations), telemetry inaccuracy could produce relatively large variability in fractal dimension estimates. Therefore, in addition to the full data set, we analyzed the relationship of fractal dimension differences to percent forest cover and number of locations for the 25 plots with more than 90 telemetry locations.

For both home range and fractal analysis, we used the $30-\mathrm{m}^{2}$ FGAP version 6.6 land classification, based on Landsat imagery, to differentiate forested and nonforested areas. For the purposes of this study, these data should reflect with reasonable accuracy the distribution of forest cover at the time the images were made (i.e., 1993-1994).

Forest cover was estimated over the entire home range; therefore, estimates of percent forest cover used in home range analysis should suffer little from smallscale error in panther locations. Inaccuracies in mapping of FGAP land covers are of more concern when telemetry locations are georeferenced by pixel with an FGAP-derived forest cover map. As discussed, spatial averaging compensated for some of this error in fractal analysis. Potentially greater effects occur when specific FGAP cover types are associated with specific telemetry location pixels. Were such an evaluation valid, given levels of accuracy and the precision of telemetry and vegetation representations, it would provide a characterization of the types of habitats panthers select for day beds rather than describing overall habitat use.

Although the accuracy and precision of panther telemetry observations may affect analysis results, minimizing these sources of error will not reduce the primary source of bias in habitat selection studies based on panther telemetry: the failure of telemetry monitoring to document habitat use during nondaylight hours when panthers and prey are most active. Maehr and Cox (1995) and Kerkhoff et al. (2000) are not alone in failing to acknowledge this source of error (Rettie and McLoughlin 1999).

\section{Home range analysis}

We computed home range sizes for each adult panther with greater than $1.5 \mathrm{yr}$ of telemetry-documented residence in an established range. Fifty monitored panthers, 19 males and 31 females, met these criteria. Of the 52 monitored panthers excluded, some were juveniles moving within the natal range, some were transient subadult males with no established area of habitual use, and the rest were resident panthers with less than $1.5 \mathrm{yr}$ of tenure in their home ranges. For panthers collared as adults with established ranges, we included all radiolocations; for panthers collared as juveniles, we examined movements within the natal range using the ATLSS PanTrack movement animation display, noted dispersal events and transient subadult movements, and included in our analysis only those locations collected after the starting date of residency within what would eventually constitute the home range.

The atypical ENP male \#16, "Chekika," was excluded from home range analyses because it was impossible to compute a home range size for him that was functionally comparable to those of other panthers. His disjunct range, which included activity areas west of Shark River Slough during years when no mates were available in his original range east of the Slough, was about three times larger than the next largest male range and included a wide transit-way across the Slough.

The minimum convex polygon (MCP) method (Mohr 1947, Seidensticker et al. 1973, White and Garrott 1990) was used to define home range boundaries. Once defined, the polygon for each home range was used to extract a corresponding polygon from a georeferenced FGAP habitat map. Percent forest cover in the polygon was then computed using the aggregation of FGAP forest types. The strength of the relationship between percent forest cover and home range size for all 50 panthers combined, as well as males and females separately, was then evaluated using correlation analysis.

Several other methods were used to depict activity within home ranges. The MCP method was applied to the telemetry locations to define a yearly activity range for each monitored panther. The degree of overlap of yearly ranges was computed by overlaying all activity polygons for a given year or period of years on a common grid and summing instances of overlap (i.e., shared use, expressed as panther-years of occupancy) 
for each pixel. Home range use was also depicted as movement buffer areas around individual telemetry observations. The buffer chosen was a circle with a radius equal to the mean movement distance between sequential telemetry locations $(6.6 \mathrm{~km}$ and $3.2 \mathrm{~km}$ for males and females, respectively), as suggested in Rettie and McLoughlin (1999). Because multiple use of a location is germane to this evaluation, all telemetry observations were used $(N=49,889)$. As with the activity polygon overlays, overlays of many buffer areas indicate the intensity of habitat use. The color-coding of levels of use intensity on graphics was generally scaled to display zones of low intensity in blue, shading to zones of high intensity in magenta. These depictions of possible habitat use around telemetry points inferred activity patterns during the unsampled (including nondaylight) periods between monitoring flights.

\section{Fractal analysis and conditional mapping}

Fractal analysis and conditional mapping were conducted on the entire 1981-2000 data set of telemetry locations to test hypotheses regarding relationships between local extent of forest cover and panther resting locations and, if such relationships were found to exist, to explain them in terms of panther behaviors. Analysis of a 1981-1993 subset was directed toward comparison to and evaluation of results reported by Kerkhoff et al. (2000) for a spatial subset of these data.

To implement the fractal analyses, we overlaid a uniform $8 \times 8$ grid of plots (numbered 0 to 63 in column order from the upper left to lower right map corners) on the study area (Fig. 2). Each of the 64 plots contained $700 \times 70030-\mathrm{m}^{2}$ pixels. Some plots (e.g., in the Gulf of Mexico) included no land cover classes. We chose this uniform plot layout to minimize the sampling bias (i.e., a systematic pattern of over- and undersampled pixels) associated with the two-tiered approach of Kerkhoff et al. (2000). In addition to restricting sampling bias to the outer map edges, the uniform plot facilitated straightforward evaluation of spatial trends, which are important in the heterogeneous environment of South Florida. However, to better understand the results of Kerkhoff et al. (2000), we also repeated their analysis of the 1981-1993 data set using the two-tiered sampling configuration.
Fig. 2. Uniform plot configuration used for our comparison analysis set.

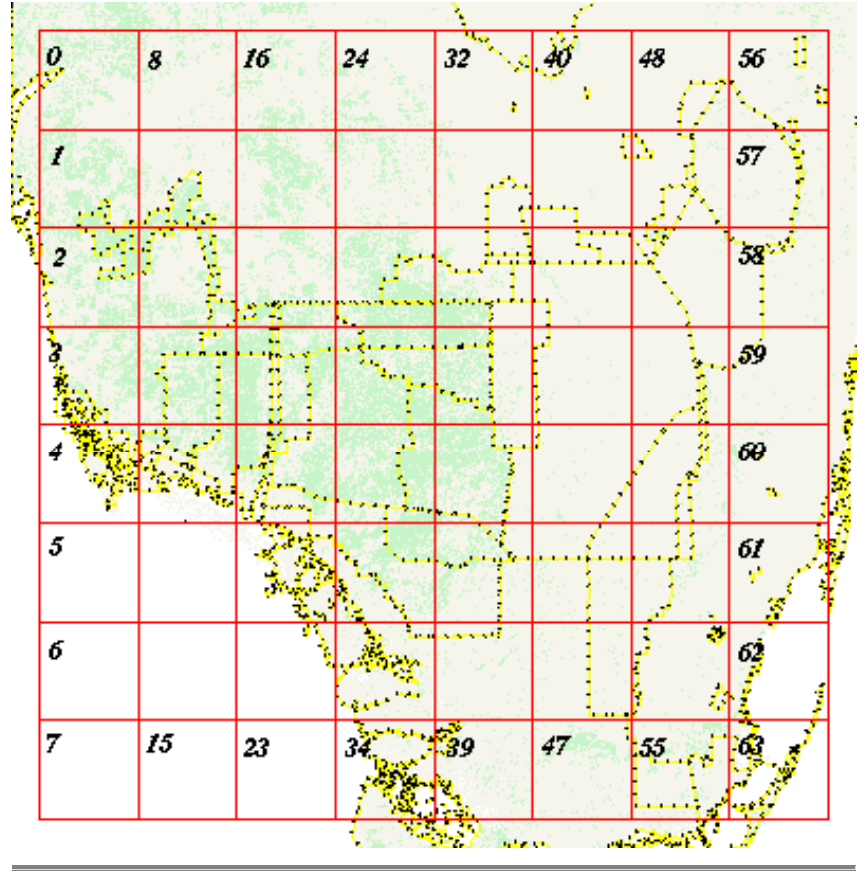

Fractal analysis was conducted at the pixel level. Telemetry locations were assigned to $30^{2}-\mathrm{m}$ pixels to allow spatial analysis with FGAP-derived forest cover. Thirty-nine grid plots contained at least one location. Of the 25 "empty" plots, 10 (Plots 4-7, 13-15, 22-23, and 31) were located in the Gulf of Mexico and along the coastal mangrove forests, habitats that panthers do not frequent. Plots 32, 33, 40, 41, 48, and 49 covered the southern tip of Lake Okeechobee and the Everglades Agricultural Area (EAA) to the south, where panthers are excluded by open water and agricultural activity. The plots covering the Water Conservation Areas (WCAs), i.e., 42-44, 48-53, and 57-58, had few or no panther locations. The plots with more than 1000 locations were found in a contiguous zone (Plots 11, 18-20, 26-28, 34, and 36), centered in BCNP and in Plots 46 and 47 in ENP. Of the 39 plots with at least one panther location, three (Plots 21, 30, and 33) had five or fewer locations, another five (Plots $0,2,8,24$, and 50) had fewer than 25 locations, and six others (Plots 1, 16, 42-44) had fewer than 90 locations. Twenty-five plots had more than 90 locations.

A series of eight square windows ranging in width $(L)$ from 210 to $9210 \mathrm{~m}$ (i.e., 7 pixels to 307 pixels) and centered on each FGAP-derived forest pixel in each plot was used to compute the number of pixels with forest cover within each window for each centered 
forest pixel. To ensure that windows of all the required sizes lay within the map boundary, the entire $8 \times 8$ grid was inset 200 pixels from the outer edge of the $6000 \mathrm{x}$ 6000 pixel study area. For each plot and window size, the window sums for pixels with forest cover were then averaged, yielding a "forest " measure $F(L)$. Conditional mapping was then used to derive a similar measure $H(L)$ for forest pixels associated with panther locations by excluding from plotwise averages data for those pixels that did not have a panther observation within the particular window boundary.

Doubly logarithmic regression analyses were performed on values of $F(L)$ and $H(L)$ vs. window size for each plot. The slopes of these regressions provided estimates of the mass fractal dimension of forest areas $(D)$ and forested areas near panther observations $(E)$, respectively. Values of $F(L)$ and $H(L)$ were expected to converge for large window sizes, which would likely contain at least one panther observation. Values of $H(L)$ substantially greater than those of $F(L)$ for smaller window sizes denoted a relatively greater amount of forest associated with panther locations compared to the forested area as a whole, yielding a smaller slope (i.e., $D>E$ ).

To determine if the differences in $D$ and $E$ were significant over the domain of plots, paired t-tests were conducted on $D-E$. We tested the hypothesis that the mean difference was significantly greater than zero. Results were interpreted at the $\alpha=0.05$ level. We took a mean difference significantly greater than zero as an indication that panther daytime locations were associated with areas that were typically more forested than the general landscape. We also used the $8 \times 8$ grid plot design to calculate percent forest cover and number of panther locations. We related percent difference in $D$ and $E$ ( $P D$, expressed as [ $D$ $\left.E) / D)^{*} 100\right]$ ), to these variables at the plot level through correlation and regression analyses.

In addition to the full 39-plot data set, a 25-plot subset of fractal analysis results (plots with fewer than 90 locations excluded) was analyzed. For each of these two data sets, analyses were also conducted with the (one or two) negative values of $P D$ removed. For these "positive value" data sets, regressions of logtransformed values of $P D$ vs. percent forest cover and number of locations were also evaluated.

Kerkhoff et al. (2000) applied similar fractal analysis techniques to a spatial subset of the 1981-1993 telemetry data set. The hypothesis they tested extended beyond daytime site selection to panther habitat selection for all life cycle requirements. They concluded that panthers preferred locally dense (unfragmented) forested areas, that a threshold of $25 \%$ forest cover defined the lower limit of panther habitat suitability, and that forest could therefore be considered a surrogate for useful panther habitat. Their paper provides little discussion of results in terms of observed home-range attributes and activity patterns of monitored panthers in South Florida. To better understand the implications of their results, we analyzed the 1981-1993 data set using both our uniform plot configuration and a two-tiered overlapping plot configuration (using a 6 x 6 overlapping grid) similar to that used in Kerkhoff et al. (2000). We compared our results using the overlapping plot configuration to those provided in Kerkhoff et al. (2000) to evaluate the consistency of the two analyses through correlation of results.

\section{Analytical tools}

Landscape and telemetry analysis applications were written using PV-WAVE (Visual Data Analysis Software by Visual Numerics). Home-range analysis applications were written as extensions to the ATLSS PanTrack Telemetry Visualization Tool, also using PV-WAVE (http://www.tiem.utk.edu/ ecomiske/ HTML/Everglades/Software/index.html). PanTrack was also used to display selected radiolocations and home range polygons over landscape maps as well as to compute statistics from telemetry data, including home range sizes, distance moved between sequential observations, dispersal distances, and other metrics as needed. Statistical analysis using home-range and fractal analysis results were run under SAS Version 8.3. Computations for fractal analyses were performed on the Scalable Intracampus Research Grid at the University of Tennessee (http://www.cs.utk.edu/sinrg/) using a computing cluster of 16 nodes running Solaris 7.

\section{RESULTS}

\section{Home range size}

We evaluated the relationship between home range size and percent forest cover for 50 adult panthers with established home ranges where they had been residing for more than $1.5 \mathrm{yr}$. We expected that, if panthers are highly dependent on extensive tracts of forest cover, home range size would show a strong inverse relationship to percent forest cover, as proposed by 
Kerkhoff et al. (2000). Furthermore, if there is a threshold of forest cover below which a landscape is unsuitable as panther habitat, we would find no panthers with home ranges below this threshold. The presence or absence of such relationships has profound implications for conservation and management strategies, from the estimation of carrying capacity to the establishment of priorities for habitat protection.

The results of our analysis for 19 male and 31 female panther home ranges (Fig. 3 and Appendix 1) indicated that no significant relationship existed between home range size and percent forest cover.

Fig. 3. Panther home-range size plotted against percent forest cover within home range.

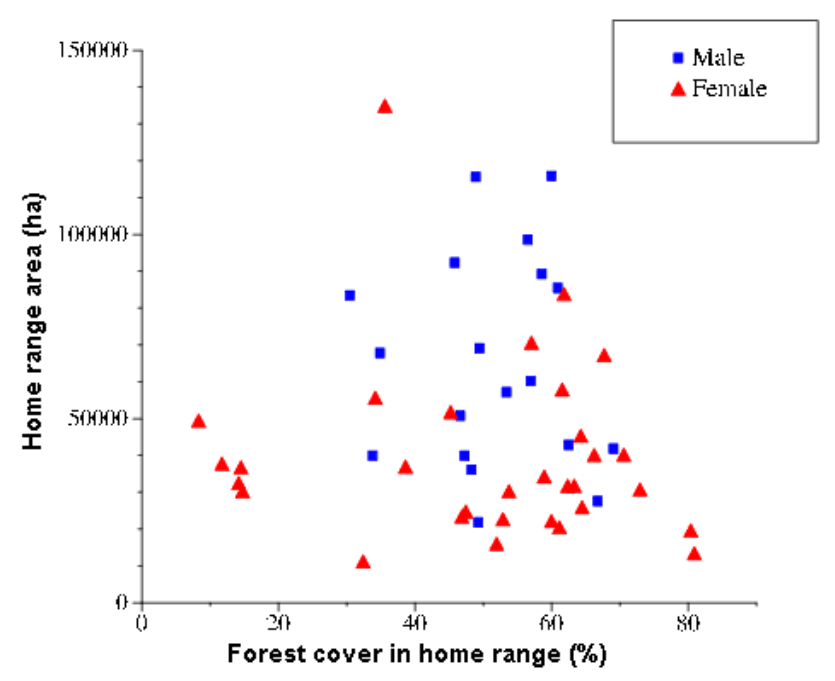

Consistent with expected trends, the mean home range size for females $(39,630$ ha) was significantly smaller than the mean for males $(65,026 \mathrm{ha})$ based on a t-test $(\alpha=0.05)$. Only 4 of 31 females had home ranges larger than 60,000 ha, whereas more than half the 19 male home ranges were greater than 60,000 ha. However, the largest male home ranges $(115,862$ and 115,648 ha) were smaller than the largest female home range (\#38: 134,922 ha). Panther \#38 was a barren female with an atypically extensive home range that included forays into Water Conservation Area (WCA) 3A. She was removed from Big Cypress National Preserve (BCNP) for medical evaluation of reproductive problems and returned to the wild when no specific cause could be found. The next largest female home range was 83,795 ha, about $62 \%$ of that for panther \#38. The smallest female home range $(11,169$ ha) was just over half $(51.2 \%)$ the size of the smallest male range $(21,799 \mathrm{ha})$. As was the case for size, female panther home ranges showed a larger range in forest cover $(8.3-80.9 \%$ vs. $30.5-69.1 \%$ for males, (Fig. 3 and Appendix 1). This is attributable to female presence in Everglades National Park (ENP), where forest cover is low, as well as in areas to the northwest, such as Fakahatchee Strand State Preserve (FSSP), where forest cover is relatively high. Despite the different ranges, the means were almost identical (51.6\% for males and $50.2 \%$ for females). The absence of male home ranges characterized by low percent forest cover is due to the exclusion from the analysis of both males from ENP. Chekika (\#16), resident in ENP from 1987 to 2000, had an early range in ENP of about 65,000 ha, but his area of activity expanded to more than 300,000 ha as he crossed Shark River Slough and explored much of BCNP during the years when no females were present. In the $5 \mathrm{yr}$ after Texas female panthers were introduced into ENP in 1995, his range returned to a more typical size of 40,000-50,000 ha. The newly resident male in ENP was also excluded because he had not yet dispersed from his natal range at the time of analysis.

The ENP panther population is separated from BCNP by Shark River Slough and is bounded by urban areas to the east, WCAs to the north, and coastal mangrove forests to the south. Although the size of this area may not support more than one or two males, ENP nonetheless provides viable habitat for a substantial portion of the South Florida panther population. The ENP population may become more stable if connectivity is established with BCNP as panthers colonize areas immediately to the west of Shark River Slough (McBride 2001).

The Pearson product moment correlation coefficients measuring the relationship of home range size and forest cover (-.04 and -0.12 for males and females, respectively), are not significant at $\alpha=0.05$. Percent forest cover explains less than $1 \%$ of the variability in home range size for males and a little more than $2 \%$ for females. Small home ranges are associated with high percent forest cover for only a few female panthers. Several of these (lower right of Fig. 3) belong to females living near large captive game pens at the Big Cypress Seminole Indian Reservation (BCSIR), where diets are often supplemented with exotic deer and hogs (Land et al. 1999). Other small female ranges are found in FSSP, which is bounded to the east by State Road 29 and to the west by Southern Golden Gates Estates, which has low prey density and intensive human disturbance. These and other 
covariates (e.g., range enlargement associated with a search for potential mates) contribute to the variability associated with home range size.

Our results do not support the hypothesis of Kerkhoff et al. (2000) that home ranges in habitats where forest is fragmented (with low percent forest cover) are enlarged as panthers seek to maximize forest resources. Panthers maintaining relatively small home ranges in areas of low forest cover (lower left of Fig. 3) include five females in ENP (McBride 2000, 2001; R. T. McBride, personal observation). Although geographic isolation has led to gender imbalances and other problems characteristic of a small subpopulation, panthers in ENP have a predominantly ungulate diet similar to that of panthers in other areas of South Florida (Dalrymple and Bass 1996) and suffer no apparent ill effects from low levels of forest cover.

Our results also do not support the finding of Kerkhoff et al. (2000) that areas with forest cover of less than $25 \%$ are unsuitable as panther habitat. Panthers are currently thriving in ENP in home ranges characterized by less than $10 \%$ forest cover. Any minimum percent forest cover for viable panther habitat would likely be specific to local conditions (e.g., types of cover, prey density). The absence of panthers from many plots with low forest cover can be explained by factors associated with human disturbance in a managed landscape (e.g., urban areas, water conservation impoundments, areas of intensive agriculture, and major roads that are barriers to dispersal). Our home range evaluation suggests that, rather than restricting themselves to areas of unfragmented forest, panthers in South Florida use virtually all available natural habitats except coastal mangrove forests. As the population continues to expand and recolonize vacant areas, distributional gaps that were once interpreted as demonstrating avoidance of habitat are being filled (R. T. McBride, personal observation).

\section{Fractal analysis}

We conducted a fractal analysis with conditional mapping using the 1981-2000 telemetry data, the Florida Gap Analysis Vegetation Map (FGAP version 6.6) land-cover map layer, and a uniform grid of plots over the study area to examine the relationship of panther daytime locations and forest cover. A t-test was performed to determine if mean percent difference $P D$ between fractal dimensions $D$ and $E$ (across plots) was significantly different from zero. Values of $P D$ significantly greater than zero would reflect a preference by panthers for daytime locations that are more extensively forested than the area as a whole. Bivariate relationships of $P D$ with percent forest cover and number of panther locations were evaluated through correlation and regression analysis of both the full data set (39 plots with at least one telemetry location) and one that included only the 25 plots with $>90$ locations, in accordance with the methodology of Kerkhoff et al. 2000. Some analyses were conducted with negative values of $P D$ excluded. A significant negative relationship between $P D$ and percent cover would indicate that panthers' daytime preference for locally dense forest is strongest in landscapes with more highly fragmented forest.

An analysis of the 1981-1993 data was also performed for comparison to the two-tiered grid plot approach used by Kerkhoff et al. (2000). For most plots occupied during both time periods, estimates of $P D$ were similar. Summary statistics for data sets used to characterize $P D$ and evaluate its relationships to forest cover and number of locations are provided in Appendix 2. Bivariate plots relating $P D$ to percent forest cover and number of locations are shown in Figs. 4A, 4B, and 5. Figure 6A displays the spatial distribution of telemetry locations, and Figs. 6B, 6C, and 6D display number of locations, percent forest cover, and $P D$ by grid plot, respectively. Regressions of $F(L)$ and $H(L)$ and window size used to generate $D$, $E$, and $P D$ for representative plots are shown in Appendix 3.

The mean number of telemetry locations per grid plot was 916 over all 39 plots (Appendix 2). Reflecting the data selection criteria, the minimum numbers of locations increases from four over all 39 plots to 97 over the 25 plots with more than 90 locations (Appendix 2). The maximum number of locations is 5644 (Plot 18, covering the most northwestern section of BCNP and adjacent private land). The higher numbers of locations found north of I-75 and west of Highway 29 (Figs. 6A and 6B) reflect historic monitoring patterns and the restricted pre-1995 distribution of panthers. The scarcity or absence of locations in some unforested plots can be attributed to the fact that large areas of landscape are unavailable to panthers because of intensive agriculture, water impoundments, and urbanization (see Fig. 1). Panthers have been effectively excluded from the highly urbanized Atlantic coast corridor (Plots 56-63), the WCAs, and the Everglades Agricultural Area (e.g., Plots 32, 40-41, and 48-49 as shown in Fig. 6B). 
Over the 39 plots containing at least one panther location, mean forest cover is $21.7 \%$, with a range of 0.92 to $63.6 \%$ (Fig. 6C and Appendix 2). Mean percent cover is higher $(28.3 \%)$ for grid plots with more than 90 locations, but the ranges are similar (see Appendix 2). This indicates that many but not all of the plots with small numbers of locations have low percent forest cover. Spatially, percent forest cover is highest in a large contiguous area centered in northern BCNP (Fig. 6C). In the three easternmost rows of grid plots (i.e., Plots 43-64), which include the urbanized east coast, most of the WCAs, and substantial agricultural tracts, percent forest cover is low (Fig. 6C).

Fig. 6. Spatial distribution of A) panther telemetry locations, B) mean number of panther locations per grid plot, C) mean percent forest cover per grid plot, and D) mean percent difference between the mass fractal dimension of forest areas $(D)$ and forested areas near panther observations $(E)$, expressed as $\left.[(D-E) / D)^{*} 100\right]$ per grid plot.
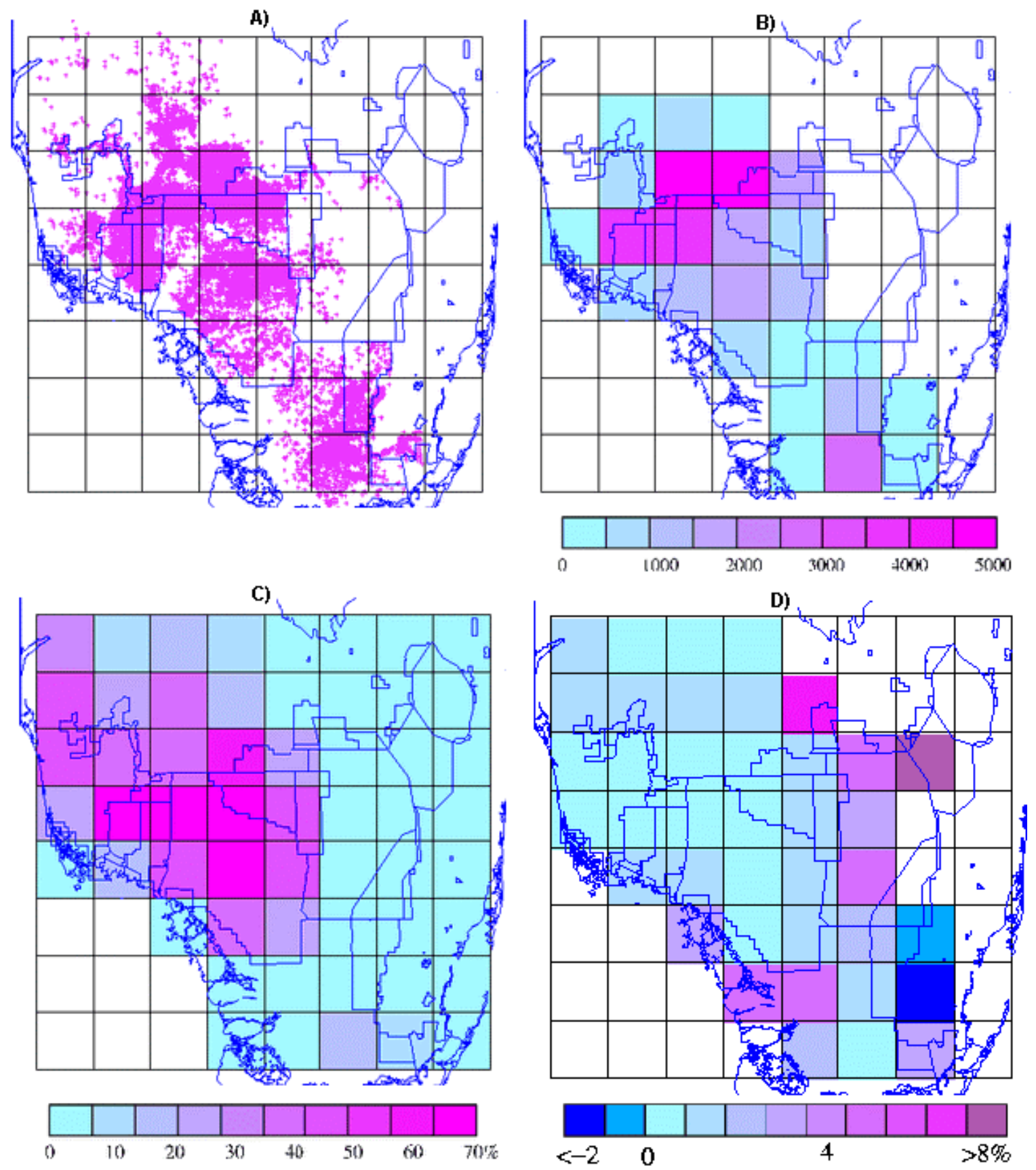
In general, the spatial pattern of percent cover (Fig. $6 \mathrm{C}$ ) is similar to that of the number of locations (Figs. 6A and 6B) except for ENP Plots 46 and 47, which have relatively high numbers of locations and relatively low forest cover. Telemetry locations in these plots substantially reflect the presence of areas of low to intermediate hydroperiod (including Long Pine Key).

Mean $P D$ is 3.11 over all 39 plots and 1.50 for plots with more than 90 telemetry locations (Appendix 2). Results of the paired t-tests indicate that mean $P D$ is significantly greater than zero for both data sets. Differences are, however, substantially more pronounced when negative values are excluded. These results indicate that, across all plots, there is a significant tendency for panthers to seek out day beds in areas that are more forested than the local area in general.

Except for two contiguous plots (Plots 53 and 54) covering the western edge of ENP and private land to the east (Fig. 6D), $P D$ values were positive. The highest positive values were found in plots south and east of Lake Okeechobee (Plots 33, 42-44, and 50), and two contiguous plots (Plots 30 and 38) covering the northwest portion of ENP (including Shark River Slough and the adjacent coastal region). Forest cover in all these plots was less than 5\%. Maximum values were 30.9 (Plot 50) over all 39 plots and 8.0 (Plot 38) for plots with more than 90 locations. Plot 50, which is largely occupied by WCA $3 \mathrm{~A}$ and contains only 21 locations, has the highest value of $P D(30.9 \%)$. It was one of the few plots for which the regression of $F(L)$ and $H(L)$ vs. window size did not converge at high window sizes. For plots with more than 90 locations, the highest $P D(8.0 \%)$ was seen in Plot 38 (with 143 locations), which includes the area near the mouth of Shark River Slough. In plots with more than 25\% forest cover, the maximum $P D$ value was 2.38 . Thus, eliminating plots with few panther locations eliminated most but not all of the large values of $P D$, whereas plots with more than $25 \%$ forest cover included none of the larger values. $P D$ values were uniformly low across all the BCNP plots as well as those immediately to the north and west, where many telemetry locations were reported and percent forest cover was relatively high (Figs. 6C and 6D).

ENP Plot 54 (with 262 locations and $1.23 \%$ cover) had by far the larger of the two negative values of $P D$ (14.72). This negative value was interpreted as indicating that the panther(s) responsible for telemetry locations in this largely nonforested area were selecting sites that were less extensively forested than the local norm. The only other plot with a negative value of $P D$ was the adjacent Plot 53. Plot 54 included primarily agricultural and urban cover classes but also contained the easternmost portions of ENP.

Agricultural land covers more than 54\% of Plot 54, with urban areas accounting for another $31.2 \%$. The natural habitat $(14 \%)$, consisting primarily of marshland with scattered patches of shrubland and forest, is found mostly in ENP along the western edge of the plot. Chekika (\#16) accounted for most of the panther locations in Plot 54. An overlay of his radiolocations in Plot 54 on the FGAP cover map revealed that his daytime locations were associated with forest cover about $1.1 \%$ of the time. Almost $57 \%$ of his sites were in agricultural areas, $21 \%$ were in Muhly grass, $8 \%$ were in shrubland, more than $10 \%$ were in marshland, and about $2 \%$ were in locations classified as urban-residential settings; this is consistent with percent composition of the area as a whole, indicating that he either engaged in atypical daytime activity or rested opportunistically in small patches of cover. Chekika was found dead in an agricultural field in the populated $81 / 2$ Square Mile area in January 2000 at age 14.

Plot 53 also contained (on its eastern side) substantial areas of urban and agricultural cover, but included (on the west) an area of freshwater marsh interspersed with tree islands. Visual inspection of radiolocation overlays on the FGAP version 6.6 habitat map revealed that panther locations in Plot 53 were typically located near the edges of scattered tree islands, some of which are up to a mile in length and $1 / 4$ mile across. This association with edge rather than tree island interior could explain the modest negative $P D$ value.

The relationships of $P D$ to both forest cover and number of panther locations (Figs. 4A and 4B) appear to be linear and negative at levels of forest cover greater than about $10 \%$ and numbers of locations greater than about 500. Below these thresholds, there was substantial variability in $P D$ values $(-14.72$ to $30.87 \%$ ) and curvilinearity associated with the positive values. The similarity of the two relationships derives in part from the significant positive relationship between percent forest cover and number of panther locations $\left(R^{2}\right.$ of 0.34 over 39 plots as seen in Fig. 5). About one-third of the variability in these two parameters is shared (Appendix 2). 
Fig. 4. Bivariate plots of A) $P D$ and percent forest cover and B) $P D$ and number of locations for all panther locations recorded during the period 1981 to mid-2000. $P D$ is the difference between the mass fractal dimension of forest areas $(D)$ and forested areas near panther observations $(E)$, expressed as $[(D-E / D) * 100]$.

A)

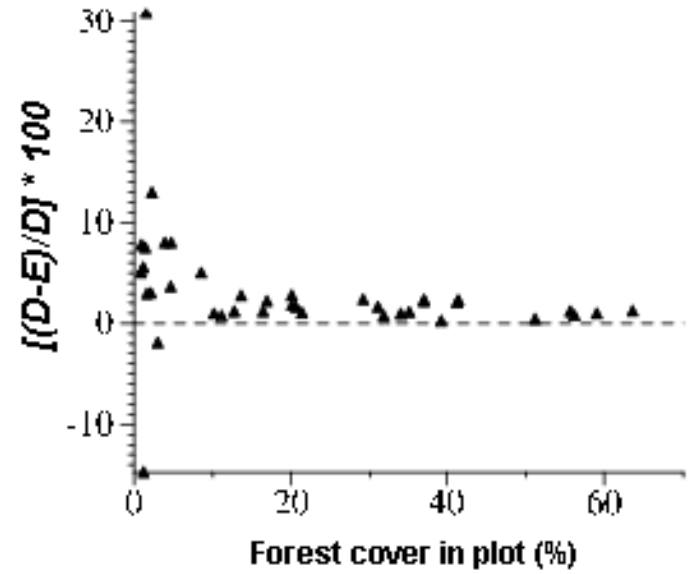

B)

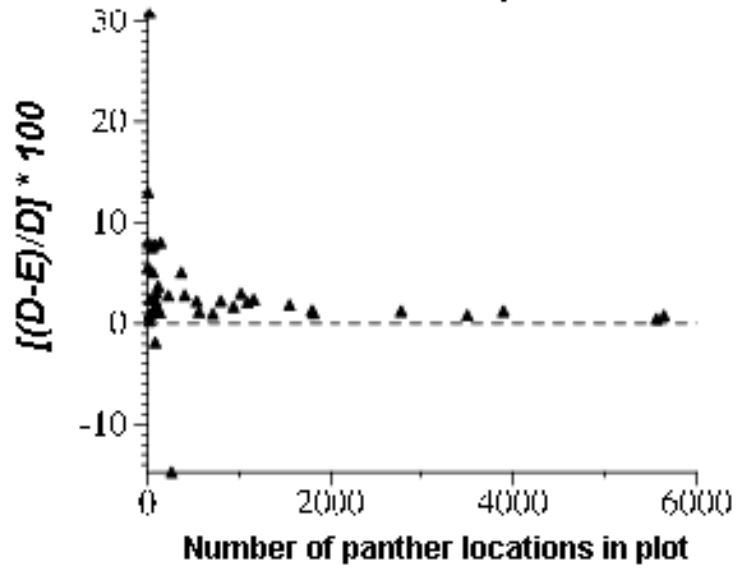

Fig. 5. Bivariate plot of percent forest cover and number of locations for all panther locations recorded during the period 1981 to mid-2000.

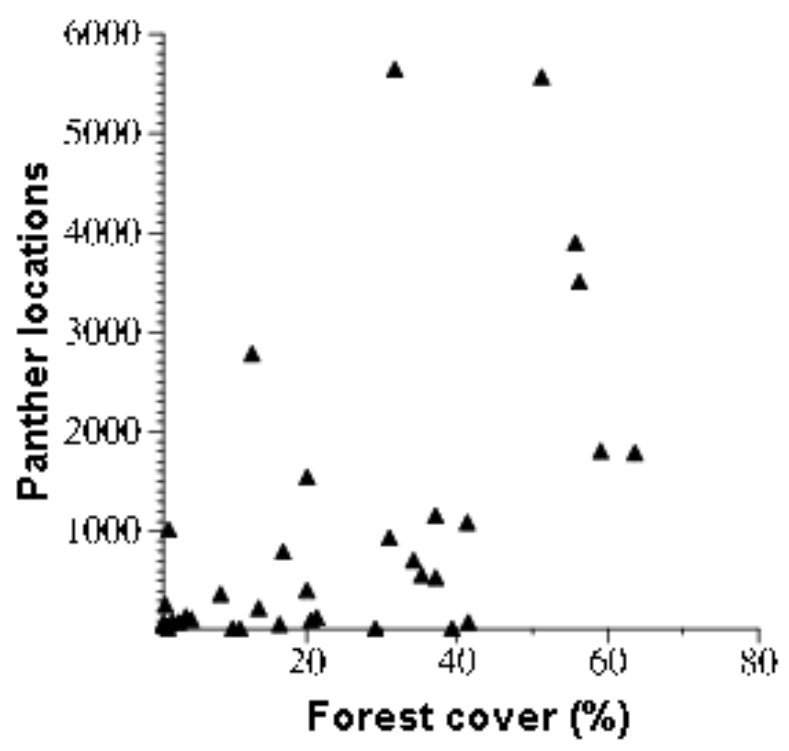

The strength of the relationships of $P D$ to percent forest cover and number of locations depends largely on the presence or absence of the two negative values of $P D$, particularly the large negative value for Plot 54 . With negative values included, the relationships of $P D$ to percent cover and number of locations are not significant (Appendix 2). With negative values removed, the situation is different. $P D$ is significantly and negatively correlated with percent cover over both data sets, and significantly and negatively correlated with number of locations for plots with more than 90 locations. The relationship between $P D$ and percent cover is not significant, whereas that between $P D$ and number of locations is barely significant.

The substantially higher variability of $P D$ at low percent cover is partly attributable to low numbers of telemetry locations (in some plots as low as four or five locations), probably insufficient for defensible fractal analysis. As discussed in Methods, the average telemetry monitoring error is about the same as the smallest fractal analysis window size. The impact of telemetry error on estimates of $P D$ would be expected to be greatest in the most highly fragmented landscapes. Even so, some of the variability in $P D$ values at low percent cover is almost certainly attributable to the influence of other factors on resting site selection.

The high values of $P D$ in some plots with fragmented (i.e., low percent forest cover) forest impose curvilinearity on the relationships of $P D$ and both percent cover and number of locations (Figs. 4A and 4B). With negative values excluded, log-transformed values of $P D$ are more strongly correlated with both percent forest cover and number of locations $\left(R^{2}\right.$ of 0.490 for the data set with more than 90 locations) than the untransformed data (Appendix 2). Plots of residuals vs. predicted values (not shown) indicate that $\log$ transformation of $P D$ substantially linearizes the relationship between (positive values of) $P D$ and percent forest cover. However, even with transformed data, less than half the variability in $P D$ is shared by 
either percent forest cover or number of locations. This indicates that factors other than forest cover are at work in determining panther site selection.

Our results indicate that panthers show a modest tendency to seek out daytime sites that are locally more forested than the area as a whole. All of the largest values of $P D$, both positive and negative, occur in plots with low percent forest cover, whereas the smallest $P D$ values occur consistently in plots with large numbers of panther locations and high forest cover. The trend for panther-associated forest to be more extensive than the forest at large decreases rapidly at percent forest cover greater than about $10 \%$. In most plots with less than $10 \%$ forest cover, panthers showed a relatively stronger tendency to select daytime sites in the interiors of forest patches. Exceptions (e.g., Plots 53 and 54) appear to have ecologically based explanations. The tendency for panthers to seek resting areas more forested than the area average does not vary significantly (is uniformly small) for plots in which forest cover exceeds $25 \%$ (Fig. 4A). These results appear to be consistent with field observations about panther resting-site selection.

Our results also indicated that the plots in which panthers showed the highest daytime affinity to forests were the ones in which panthers were least frequently found. Most plots for which $P D$ is greater than $2 \%$ contained few panther locations and typically included large areas of unsuitable habitat such as coastal, urban, intensive agriculture, or water conservation areas (see Fig. 1). Segregation of panther locations in subareas of these plots likely contributed to spuriously high values of $P D$.

Our results support the view that the adaptable panther exploits a wide variety of habitats and finds adequate resting sites in areas with highly fragmented forests as well as in extensively forested tracts. These results confirm those of our home range analysis, which show that panthers are capable of exploiting landscapes with minimal forest cover. Our findings are inconsistent with those of Kerkhoff et al. (2000), who found that $25 \%$ forest cover was the lower threshold for habitat suitability for panthers. We found that low percent forest cover alone did not preclude panther occupation. Five females and one male occupied home ranges in ENP in areas with highly fragmented forest and percent cover of less than $15 \%$. The absence or low numbers of panther locations in some plots with relatively low percent forest cover can be explained by factors other than the absence of forest cover, such as the presence of impoundments and large-scale agriculture, historical patterns of extirpation, and barriers to female dispersal. The influence of such factors was not addressed by Kerkhoff et al. (2000). We found no support for extrapolating findings about daytime site selection to overall panther habitat use (i.e., no support for the inference that panther habitat use is functionally limited to forest).

\section{DISCUSSION}

Our analyses suggest that reported associations between forest metrics and daytime panther locations (Maehr and Cox 1995, Maehr 1997a, Kerkhoff et al. 2000) do not adequately explain panther habitat use in South Florida. Our evaluation, which used the entire set of telemetry data as well as related field observations, supports earlier findings that day bed cover is often associated with forest, and that forest is an important component of a panther's home range. However, we found no direct relationship between forest cover and panther home range size and no minimum threshold of forest cover necessary for the support of panthers. Fractal analysis of daytime telemetry indicated that panthers were somewhat more likely to select forest patches that are larger than the local average as resting sites. This selection preference was more pronounced in areas of fragmented forest than in areas with larger forest stands, where the values of the percent difference between the mass fractal dimension of forest areas and forested areas near panther observations $(P D)$ were typically less than $2 \%$. The relationship of $P D$ to percent forest cover was negative and significant at forest cover of less than $25 \%$. These results are consistent with a propensity of panthers to seek protected resting sites at some minimum distance inside patches of dense cover. In a small patch, that minimum distance would be located nearer the center than it would be in a larger patch, resulting in elevated values for $P D$ in areas of fragmented forest.

We found no indication that all panther activity occurs in forest, that panthers require large expanses of unfragmented forest for survival, that panthers require only forested habitat, or that only forest merits protection as panther habitat. The preponderance of data indicate that most panther activity is nocturnal and coincident with prey activity, that panthers move widely within extensive home ranges, and that they exploit a broad spectrum of natural habitats, including but not limited to forests. Healthy panthers are currently living and reproducing in areas of highly 
fragmented forest in Everglades National Park and Big Cypress National Preserve.

Our evaluation identified four factors of particular relevance to interpretation of panther habitat associations in South Florida: (1) the biases and limitations of the telemetry data, (2) panther home range attributes, (3) habitat use beyond resting and denning, and (4) historical patterns of extirpation and dispersal. The influence of each of these factors on our understanding of panther population dynamics is discussed in the following sections, followed by a discussion of implications for panther habitat preservation and management.

\section{Data limitations}

The available telemetry data on panthers should not be considered representative for three main reasons:

- the failure of daytime telemetry to capture habitat use during hours of peak activity;

- incomplete spatial sampling, especially in the early years of the monitoring program, with a bias toward forested areas within the occupied range; and

- recent changes in population size and distribution that cause data from the early years of the program to be unrepresentative of current population trends.

Each of these factors is considered in the following paragraphs, followed by a discussion of their impact on overall data sufficiency.

\section{Bias of daytime telemetry}

The limitations of daytime telemetry data are well known (Resources Inventory Committee 1998, Rettie and McLoughlin 1999). In the case of panthers, monitoring protocols restrict radiolocations to daytime observations. However, panthers are most active from dusk to dawn, responding to increased prey activity, the protective cover of darkness, and the absence of daytime heat. They are typically at rest in dense cover during daylight hours when telemetry flights are made (Land 1994). Daytime telemetry is useful in documenting overall panther distribution patterns, delineating home ranges, locating denning sites, and recording dispersal events. Although these data are of limited usefulness in defining overall habitat use, they have nevertheless been used without qualification to characterize panther habitat requirements as well as to define "preferred" and "avoided" habitats in South Florida (Maehr and Cox 1995). One of the unstated assumptions of this analysis is that patterns of daytime activity and habitat use are representative of nighttime patterns as well. This assumption is inconsistent with the results of a limited 24-hr monitoring study in Florida (Maehr 1991), as well as field observations made over the 21-yr monitoring period by the project houndsman following tracks and fresh panther scent trails with dogs in predawn hours (R. T. McBride, personal observation). The preponderance of scientific literature on Puma concolor (e.g., Young and Goldman 1964, Tinsley 1987, Alderton 1993, Maehr $1997 b$ ) supports the view that panthers are most active at night, frequenting a variety of habitats as they hunt and otherwise move widely about their home ranges. In the case of Florida panthers, substantial nighttime activity is also strongly indicated by the large distances separating sequential day-bed radiolocations (means of $6.6 \mathrm{~km}$ for males, $3.2 \mathrm{~km}$ for females). One approach to characterizing 24-hr habitat use in such situations is the use of buffer areas around each daytime radiolocation of radius equal to mean daily movement distance (Rettie and McLoughlin 1999), which we apply in the discussion below.

For species such as the panther that exhibit distinct diurnal activity patterns, monitoring data collected at intervals around the clock would be required to be fully representative of panther habitat use. Because it has not yet been practical to implement such a design for panthers, bias in the panther telemetry data should be explicitly recognized in the monitoring reports and interpretive papers that use these data.

\section{Incomplete spatial coverage of monitoring efforts}

The current occupied range of panthers in South Florida encompasses a wide variety of habitats, including seasonally flooded prairies, cypress swamps, hardwood hammocks, pine flatwoods, freshwater marshes, and different types of agricultural lands. A habitat gradient roughly corresponding to elevation is evident moving from upland forests in the northwest to wetlands interspersed with small tree islands in the southeast.

Whereas current monitoring covers the known extent of the panther range in South Florida, early monitoring (1981-1986) was conducted primarily in the northwestern part of the range. Two panthers were captured and collared in the Fakahatchee Strand in 1981. By 1986, a total of 12 panthers had been captured; of the six being actively monitored, five had 
ranges in this same area. Capture efforts gradually expanded to include Big Cypress National Preserve (BCNP), private ranches, the Big Cyrpess Seminole Indian Reservation, and Everglades National Park (ENP). Panthers were first collared in ENP during the 1986-1987 capture season (Bass 1994, Smith and Bass 1994). By the early 1990s, no extensive panther habitats remained unexplored, and very few panthers remained uncollared (McBride 2000). At that time, the monitoring program included 24 radio-collared panthers and covered most of the occupied territory. Current monitoring includes panthers from most sectors of the expanded range. Incomplete and changing spatial coverage of the population over time must be explicitly recognized when interpreting results. In our evaluation, such considerations are most relevant to the fractal and related analyses that are based on the number of telemetry locations within geographically based grid plots.

\section{Temporal changes in population size and distribution}

Prior to the initiation of genetic restoration efforts in 1995, the panther population was estimated to include between 30 and 50 individuals. McBride (2001) has analyzed capture success rates and other supporting evidence, such as roadway mortalities, tracks, deer kills, denning activity, use of highway crossings, and documented kitten survival, recorded over the past 21 yr. His findings confirm that the population was static or declining between 1981 and 1995, but has increased dramatically in both numbers and spatial extent of the range since genetic restoration began (McBride 2001, Shindle et al. 2000, 2001). The current verifiable panther population of 78 adults and juveniles is about twice the preintrogression population and includes a five-fold population increase within habitats in BCNP and ENP considered unsuitable for panthers under forest-centered criteria.

Because recent demographic trends diverge sharply from those seen earlier in the monitoring period, evaluations that do not consider postintrogression data present an incomplete view of panther habitat associations. In addition, key analyses have excluded spatial and temporal subsets of accumulated monitoring data available at the time of analysis. For example, Maehr and Cox (1995) included only 23 of the 36 panthers monitored during the time period selected for their analysis (1985-1990), excluding more than 6000 observations from areas of fragmented forest cover in BCNP and ENP (over $40 \%$ of available data). Kerkhoff et al. (2000) excluded post-1993 data as well as all data from plots in ENP with fragmented forest, although their study purported to be representative of the currently occupied range. Neither paper provided a rationale for data exclusions. Whereas reasons sometimes exist for selecting data subsets for analysis, studies can be more easily evaluated when these reasons are explicitly given. Resting site cover throughout the range is often associated with forest of some type; however, the role of resting sites in panther ecology becomes clearer when the complete data set is evaluated, providing a broader context within which daytime telemetry can be interpreted. For example, Maehr and Cox (1995) reported an inverse relationship between home range size and percent forest cover within the home range in the spatially restricted pre-1995 population, thus reinforcing a focus on forest resources. Kerkhoff et al. (2000) posited the same relationship for the current population, suggesting a $25 \%$ threshold requirement of forest cover for viable home ranges. However, analysis of the full spatial and temporal data record reveals no significant relationship between home range size and forest cover, and documents successful home ranges in areas of relatively sparse and fragmented forest cover. These findings place the role of forest in perspective as one vital component within the extensive mosaic of habitats that make up home ranges.

\section{Data sufficiency}

In forest-centered characterizations of panther habitat use, daytime telemetry data are assumed to be representative of 24-hr activity patterns, trends observed in more extensively forested areas of the range are considered representative of all panther habitat preferences, and conflicting recent data are excluded from analyses. Given these assumptions, preconceptions, and exclusions, it is not difficult to understand how the view that panthers are forest obligates arose. Our evaluation, which explicitly considers the reasons why panther telemetry data is not representative, has led us to very different conclusions about how panthers use the South Florida landscape.

\section{Home range attributes}

Panthers are top carnivores requiring abundant large prey and large home ranges. An adult panther's home range is an area of extensive, habitual use that provides resting and denning sites, travel routes, hunting grounds, and areas where the habitat 
requirements of prey are met. Males in South Florida occupy ranges covering, on average, $650 \mathrm{~km}^{2}$ or 65,026 ha (see Appendix 1), whereas female home ranges are significantly smaller, with a mean of 396 $\mathrm{km}^{2}$ or 39,630 ha (see Appendix 1). These home ranges vary in percent forest cover from 8.3 to $80.9 \%$ for females and 30.5 to $69.1 \%$ for males. The two monitored males from ENP were excluded from home range analysis based on the selection criteria discussed in Methods, which explains the absence of male home ranges in areas with low percent forest cover.

Plotting of individual telemetry locations within the home range polygon of an individual panther (Fig. 7A) reveals the general spatial pattern of resting sites. Evaluation of the patterns of movement between sequential locations (Figure 7B) confirms that panthers do not typically return daily to a central den site. Instead, they move about within extensive home ranges, visiting all parts of the range regularly in the course of hunting, breeding, and other activities (Shaw 1989, Maehr 1997b). Exceptions are denning females with kittens and panthers remaining near kill sites for several days. Although a straight line connecting two sequential daytime locations does not represent an actual travel route, which may be circuitous, the cumulative pattern does reflect wide-ranging movements and regular use of home range components.

Fig. 7. Home range of panther \#49, as the context for displaying A) telemetry points and B) travel vectors between sequential telemetry locations.

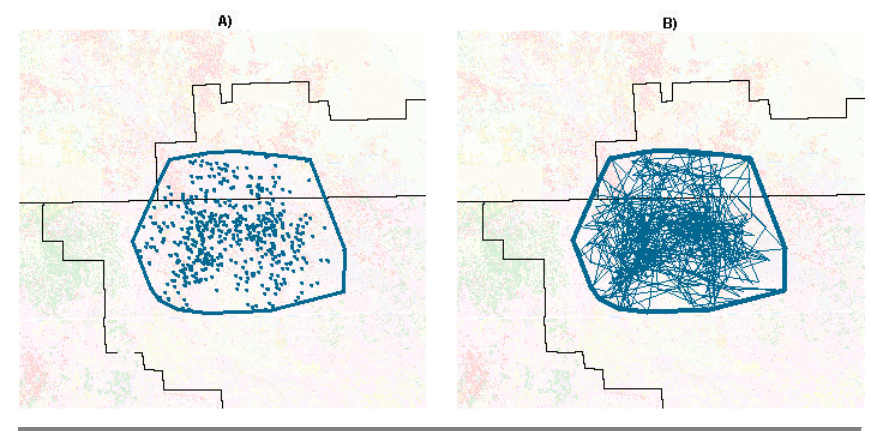

In the absence of detailed nighttime telemetry data documenting actual paths taken between daytime locations, nocturnal activity and home-range use patterns are best described by observations made while scouting and tracking panthers as part of the monitoring program (Seidensticker et al. 1973; R. T. McBride, personal observation). Observed physical evidence (e.g., tracks, scats, urine markers, and kill sites) indicate that panthers in the natural landscape of South Florida move freely within their home ranges, using or benefiting from a variety of forested and nonforested habitats. Many years of observing dogs in South Florida during predawn hunts as they follow scent trails left overnight indicate that panther movement patterns vary depending on their activity. Panthers sometimes take a direct route from one place to another, crossing a variety of habitats in the process. When hunting, their paths are typically circuitous. They visit flag ponds, alligator holes, forest edges, natural prairies, marshes, and any other sites where deer or other prey might be found (R. T. McBride, personal observation). An inspection of activity range and telemetry buffer overlays, discussed below, supports the view that, after an area has been colonized by panthers, these habitat generalists are adaptable to a wide range of natural habitats. Loss of prairies, marshes, and other open spaces fragments the habitat mosaic, resulting in diminished prey productivity and restricting access to portions of the home range. Fragmentation and human disturbance within the home range may diminish connectivity, present road hazards, restrict access to parts of the range, disrupt breeding and hunting activities, and otherwise reduce the overall carrying capacity of the range. For example, Southern Golden Gates Estates, an uninhabited subdivision development currently undergoing restoration as part of Picayune Strand State Forest, has ample cover for resting sites; however, its use by panthers is severely limited by intensive human disturbance and scarcity of prey (Maehr 1997b; M. Duever, personal observation). Nonforested areas adjacent to the home range may also serve as refuges for prey and reserves from which prey levels within the home range may be replenished (McBride 2000, 2001). Areas adjacent to current female home ranges are of particular importance to population expansion because independent ranges established by female offspring tend to overlap the natal range.

Although panthers require access to some form of cover for resting and denning sites, the proportion of a panther's home range that provides such cover is highly variable. In South Florida, home ranges in ENP typically have less than $15 \%$ cover, whereas those in the Fakahatchee Strand have up to $80 \%$ cover. In the Sonoran and Chihuahuan deserts, many miles of barren landscape separate resting sites, which make up only a miniscule portion of $P$. concolor home ranges. Nevertheless, panthers thrive there, using or benefiting from all parts of the range (R. T. McBride, personal observation). If resting sites were the only components 
preserved in these environments, panthers would not survive. Similarly, identifying only resting site habitat in South Florida for protection, while discounting other requirements, would lead to fragmentation and diminished utility of the landscape to panthers.

Kerkhoff et al. (2000) hypothesize that the primary determinant of panther habitat quality in South Florida is the amount of forest cover and that panther homerange size is determined by efforts to maximize access to forest resources. Our analysis of panther homerange size and habitat composition finds no evidence for such an inverse relationship or for the existence of a substantial threshold amount of unfragmented forest cover required for viable panther habitat (see Fig. 3). A complex interplay of density-dependent and independent factors is known to affect the size of a panther's range (Hornocker 1969, Seidensticker et al. 1973, Belden et al. 1988; R. T. McBride, personal observation), including:

- $\quad$ availability of prey;

- gender, age, and reproductive status of panthers;

- availability of mates;

- territorial behavior;

- competition and social dominance;

- availability of habitat for expansion; and

- geographic or man-made features (e.g., highways or large expanses of water) that act as barriers to movement into adjacent habitat.
In areas with high prey densities, panther home ranges tend to be smaller, although territorial behavior likely limits the minimum size of male ranges (Seidensticker et al. 1973, Anderson 1983, Hemker et al. 1984). A vigorous male in his prime can maintain a larger home range than a weaker or older male (Seidensticker et al. 1973). Both male and female panthers may enlarge their ranges in search of mates when no suitable mate is near (e.g., Chekika, male \#16 in ENP and eastern $\mathrm{BCNP})$.

The home ranges of male panthers overlap to some degree, although neighboring males rarely use the shared portion during the same time period. Polygons of the range of yearly activities typically show a greater degree of overlap than do polygons representing activity boundaries for shorter periods of time (Figs. 8A and 8B).

The home ranges of resident male panthers generally encompass the home ranges of breeding female panthers and their offspring (Maehr 1997a, Shindle et al. 2000, 2001). Substantial portions of the ranges of four female panthers lie within the range of male \#12 (Fig. 9A). This figure also illustrates the tendency for female home ranges to overlap. Panther reproduction and recruitment depend on the productivity and stability of such "breeding units" and their connectivity with other breeding units.

Fig. 9. Overlapping activity areas of five panthers (one male and four females) that make up a breeding unit (1985-1994), expressed as A) minimum convex polygons (male range boundary shown in solid blue, female boundaries dashed) and B) intensity of use (panther days of occupation) computed from the overlap of mean daily movement distance buffers around individual telemetry locations. Blue $=$ low intensity, and magenta $=$ high intensity.

A)

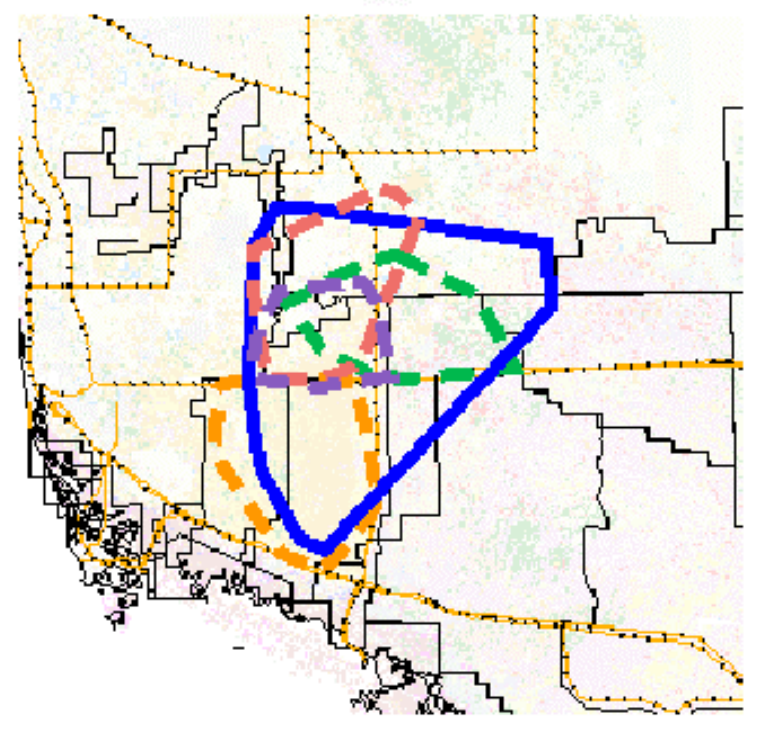

B)

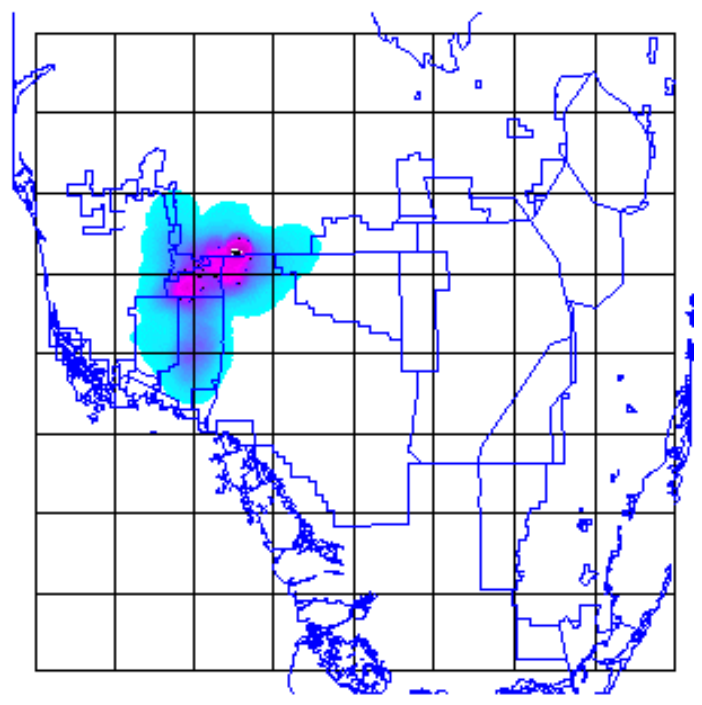


The area encompassed by the home ranges of these five panthers is about 115,800 ha, slightly more than the size of the male range alone, or about 23,000 ha (57,205 acres) each if the area were divided equally. Some subareas support greater panther densities than others. Currently, about 78 panthers (adults and juveniles) occupy an area of approximately 936,000 ha, based on the overall areal extent of the breeding range discussed below, which computes to an area of about 12,000 ha $(29,640$ acres $)$ per panther. However, such estimates of the area needed to support an individual panther are not meaningful outside the context of a breeding range in which common habitat is shared. In other words, six disjunct patches of 12,000 ha each would not support a breeding population of six panthers. The minimum size for disjunct patches would be the size of a male home range large enough to encompasses the ranges of a number of females to which he would have regular breeding access. A high degree of connectivity to other breeding units would also be required for dispersal and immigration routes.

Fig. 10. Cumulative occupation patterns (1981-2000) of the monitored panther population expressed as A) overlap of yearly activity ranges (panther-years of use) and B) panther days of use, using mean daily movement distance buffers around each radiolocation. Color coding ranges from blue for low levels of use to magenta for high levels of use.

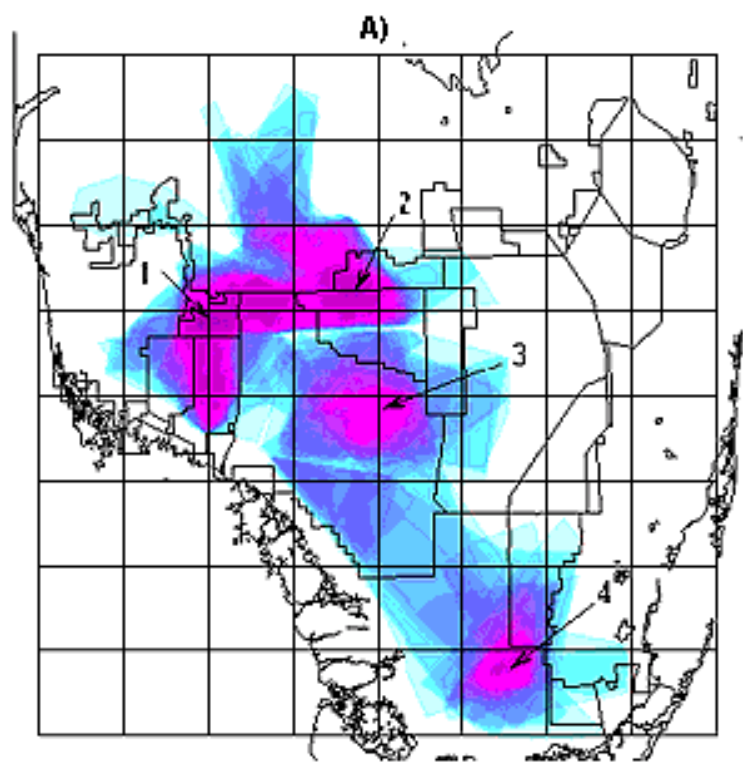

\section{Panther breeding range}

The panther population in South Florida is made up of a network of overlapping home ranges that form an integrated "breeding range" on the landscape. Figure 10 depicts the intensity of occupancy of the South Florida panther range over the monitoring period based on (1) the overlap of yearly activity ranges for each monitored panther (expressed as panther-years of activity) and (2) the overlap of mean daily movement distance buffers around individual telemetry locations (expressed as panther-days of occupancy). The depiction method used in Fig. 10A represents use within each panther's yearly activity range as uniform, whereas that in Fig. 10B represents use as a circular area around each telemetry point. The mean movement distance between telemetry points is chosen as the radius of the circle, as suggested in Rettie and

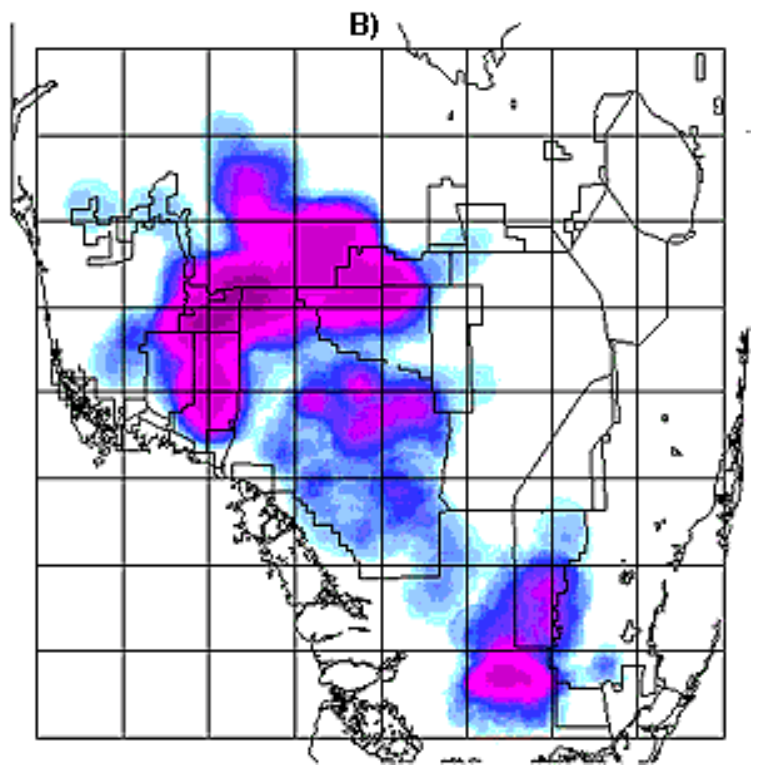

McLoughlin (1999), to correct for biases in telemetry that record only one aspect of daily behavior. The patterns of cumulative intensity of occupation of the study area by monitored panthers portrayed by these two methods are similar, although the buffered approach shows expanded areas of use. Both methods present a more complete and informative view of panther use of the landscape than do radiolocations alone.

Four centers of monitored activity emerge from this display (noted in Fig. 10A): (1) the Florida Panther National Wildlife Refuge/Fakahatche Strand State Preserve, (2) BCNP Addition Lands/Big Cyrpess Seminole Indian Reservation, (3) central BCNP, and (4) ENP. There are numerous reasons for not assuming that intensity of monitored use is a direct measure of habitat quality in these areas. Cumulative use patterns 
reflect the history and priorities of the monitoring effort in South Florida as well as changes in panther distributions over time and a host of human, environmental, and biological factors that have restricted population expansion.

In any given year of monitoring, a percentage of the population is unmonitored. The unmonitored percentage declined during the 1980s as the program expanded, reaching a point in the early 1990s when most panthers were collared. The number of unmonitored panthers is now increasing; approximately half the current verified population is uncollared (R. T. McBride 2001). The practice of the capture team of collaring the offspring of monitored females before dispersal, coupled with the strong tendency of female offspring to disperse into ranges overlapping the natal range, can lead to heavily monitored areas of panther activity. For example, the center of activity in central BCNP in Fig. 10A, Center \#3, corresponds to the range of female Texas panther TX107 and ranges of several generations of her female progeny. If all panthers in BCNP were monitored, the pattern of use would likely be more evenly distributed. Much of the activity in ENP and central BCNP is recent, corresponding to the post-1995 population expansion. As the population continues to expand, these centers appear to be coalescing (McBride 2001). Annual depictions of intensity of use that incorporate field information about the locations of uncollared panthers would be useful in documenting and investigating the nature of this expansion. Panthers have been monitored near Center \#1 since the program began in 1981, which has contributed to a disproportionate number of radiolocations there. Comparison of Fig. 10B with a similar intensity of use display for an individual breeding unit (see Fig. 9B), anchored from 1986 through 1994 by \#12, the "Bear Island Male," shows that this unit contributed substantial activity to Center \#1.

Complex interactions of factors have contributed to observed panther distributions, including human interference, reduced reproductive fitness due to inbreeding depression, and dispersal limitations. High density of use is not necessarily correlated with quality of habitat, especially for habitat generalists, where habitat quality is defined in terms of survival and reproductive success (van Horne 1983). For example, crowding caused by barriers to dispersal out of an area or lack of dispersal habitat can produce densely inhabited centers where prey is heavily hunted and kitten survival rates are low. The areas of highest activity for panthers are not necessarily those that support the highest reproduction, or those in which panthers are responding to habitat preferences. Although Center \#1 showed a high degree of occupation during the monitoring period, its contribution to reproduction has been modest. Center \#2 is located near the Big Cypress Seminole Indian Reservation, where captive prey may provide an important supplement to panther diets. Center \#3, in central BCNP, consists largely of monitored descendents of TX107, as discussed above, who was translocated there in 1995 as part of the genetic restoration program. Center \#4 in ENP is isolated from the main population by Shark River Slough to the west, coastal mangroves to the south, urban areas to the east, and Water Conservation Areas to the north. Although habitat plays an important role in panther dynamics, none of these centers appears to be unambiguously selected by panthers on the basis of preferred habitat alone.

Efforts conducted under the Across Trophic Level System Simulation (ATLSS) program have assembled detailed, georeferenced data layers characterizing the South Florida landscape. To investigate factors that affect reproductive success, we related data on cover type, water depth, geographical features, and prey availability to breeding history and movement patterns of the panther population within the context of home ranges and breeding units. A variety of telemetryderived use patterns (e.g., juvenile ranges, dispersal paths, and transient movements) was evaluated in this effort. Interpretation of observed patterns considered the development of the monitoring program, impediments to movement, and the extent to which human intervention has altered natural patterns, in addition to those environmental characteristics associated with zones of use intensity.

\section{Habitat use}

Panther habitat use is best understood in the context of the establishment and maintenance of home and breeding ranges. Individual components of panther habitat derive much of their value from the landscape matrix in which they occur, affecting home range size and quality to the extent that they contribute to meeting specific biological needs of panthers, particularly those related to reproductive success. In this regard, information about age structure, health, reproductive status, and differential rates of kitten production and survival should be considered when evaluating quality of habitat. 
Habitat selection and use studies should target those environmental features that enhance or suppress the reproductive potential of panthers. Further monitoring and research are needed to separate the effects of habitat, inbreeding, prey densities, and crowding. To assess habitat contributions to reproductive success, information about other potential contributing factors is required, including:

- documentation of relevant monitoring patterns and priorities and of known locations of uncollared panthers,

- the reproductive histories of each female panther, and

- comparative evaluations of Florida vs. introgressed reproductive fitness and kitten survival to investigate relative contributions of genetics vs. other factors to pre-1995 reproductive decline and distribution.

The forest-centered view of panthers posits a causal relationship between the amount of forest cover and the size and quality of home ranges, which implies an association with reproductive success. Such a relationship was not found in our study and is not consistent with known needs of panthers or with the dynamics of the postintrogression population. Our findings are consistent with the characterization of panthers as habitat generalists (Tinsley 1970, 1987; Guggisberg 1975) that are adaptable to the habitat of their prey (Dixon 1982). A variety of habitat configurations within a home range provide resting and denning sites, hunting grounds, and habitats that produce and nurture prey (McBride 1976). A relative lack of disturbance in terms of road hazards and human activity within a home range allows panthers to access and use all parts of the range.

From an ecological perspective, the term "forest" encompasses a wide range of habitats in South Florida, not all of which are equally beneficial to panthers. The primary benefit of forest habitat is a dense understory that provides resting and denning sites and hunting cover where forests interface with open areas. Preferred cover for denning and resting is dense vegetation close to the ground, such as saw palmetto, cocoplum thickets, fern beds, and oak scrub (McBride 2001). Not all suitable cover is found beneath forest canopies. For example, in 2001 two panther dens were found in sawgrass. The first was found on the Okaloacoochee Slough Wildlife Management Area (OK Slough), hidden in a sawgrass slough within 100 yards of an oak hammock. The second was found in southern BCNP within sight of a cypress strand and oak scrub with palmettos. Although forests were available, these panthers chose the denser sawgrass cover for their dens. Although these den sites are not typical, they demonstrate the use of the mosaic of habitat types within panther home ranges.

Different types of managed and natural forests vary in terms of the quality of cover the provide for panthers. For example, cypress domes on public land generally have a dense ground cover of large ferns that make ideal day beds for panthers, whereas cypress and other forests on private land where cattle graze may have no cover beneath the canopy. Mature closed-canopy forests often support only sparse understory and provide little suitable cover for panthers (McBride 2001). The presence or absence of forest understory is generally not discernible from the aerial photographs and remotely sensed images from which much of the land cover information available for South Florida is derived. Our ability to assess the utility of specific forest patches for panthers from these images is therefore limited. Vegetative structure, successional stage, and proximity to open spaces where prey are nurtured and stalked all contribute to the utility of forests for panthers. Evaluations of panther habitat use based on such a broad landcover classification do not identify the specific elements of forests that benefit panthers.

Literature on $P$. concolor indicates that panther habitat quality and home range size are closely related to prey production (Anderson 1983). Panther activity cycles and habitat use patterns are coordinated with those of their primary prey, which in South Florida are whitetailed deer and feral hogs (Schortemeyer 1994). In the Everglades, deer are adapted to a mosaic of wet prairie-tree island-marsh environments of intermediate hydroperiod (Fleming 1994). High-nutrient deer forage, preferred especially by females, includes the hydrophytic marsh plants white waterlily (Nymphaea odorata) and swamp lily (Crinum americana). Wetland willow thickets (Salix sp.) provide nutritious browse for both males and females (Loveless 1959). Large amounts of edge and interspersion of habitats have beneficial effects on deer density (Miller 1993). In upland landscapes, deer are most abundant where areas subject to frequent fire are interspersed with stands of protected hardwoods. Late successional forest stages typically produce low-quality forage, and deer densities in extensively forested areas consequently tend to be low. Deer spend much of the daytime in secure cover, foraging at night in open areas, with peak activity at dusk and dawn. Panther 
activity patterns closely approximate those of deer. In Florida, deer density should be a good indicator of the general suitability of habitat for panthers.

Spatial patterns of density of deer and other prey attributable to habitat factors, hunting pressure, and water management and prey management practices also affect panther distributions independent of forest cover. Some forested areas may provide sufficient small prey for panther survival, but not enough large prey to support successful panther reproduction and recruitment. The nutritional needs of female panthers with kittens are high, and ready access to large prey is essential for the successful rearing of young (Ackerman et al. 1986). When a mother must leave her den for long periods of time to hunt, hungry kittens may become restless and wander or vocalize, attracting predators and otherwise risking injury or death. Kitten mortality is minimized when a mother is able to make successful kills near the den and return quickly to her kittens or bring them to the kill site (R. T. McBride, personal observation). Therefore, offspring in dens located in areas of abundant prey are more likely to survive the first critical months of life.

Fine-grained heterogeneity of the landscape and the large amount of ecotone associated with it are important to prey productivity. Panthers use forest edge for concealment when stalking prey feeding in open areas (Belden and Hagedorn 1993). The importance of upland forest/open prairie edge in determining the breeding density of panthers has been noted by several researchers (Belden et al. 1988, Smith and Bass 1994). The sparse understory in many closed-canopy forests makes them relatively unproductive for deer and other prey. Prescribed burning, planting of food crops, and the creation of openings are recommended in mature forest habitats to improve the quality of deer forage and increase prey productivity for panthers (McCown 1994). Efforts to improve panther habitat by creating forest openings are currently underway north of the Fakahatchee Strand within the Florida Panther National Wildlife Refuge (L. Richardson, personal observation).

The recent introduction of western cats into South Florida demonstrates that panther habitat requirements can be met by the components of diverse landscapes. Eight female Texas panthers were transported from a dry, treeless area in the northern part of the Chihuahuan Desert in West Texas to sites in BCNP, ENP, and Fakahatchee Strand State Preserve, which include some of the wettest landscapes in the United
States. The translocated panthers not only survived, but thrived and reproduced in the mosaic of marshes, swamps, prairies, small tree islands, and uplands of their new environment. The success of these Texas panthers and their intercrossed offspring in areas of highly fragmented forest has reshaped concepts of how panthers use habitat in Florida by demonstrating that the presence of unfragmented forest is not required for panther habitat suitability.

Forest cover was proposed as the primary determinant of the restricted pre-1995 distribution of panthers and of habitat quality within existing home ranges (Maehr 1997b). However, postintrogression data clearly indicate that the absence of panthers does not necessarily imply poor habitat quality, because many factors other than habitat influence panther survival and distribution. It now seems likely that reduced reproductive fitness due to inbreeding, rather than habitat quality, was largely responsible for the stagnant growth and expansion of the panther population. These events suggest the need to replace the forest-centered view of panthers with a new paradigm consistent with what we have learned about the environmental prerequisites for reproductive success.

\section{Historical patterns of extirpation and dispersal}

Panthers once populated much of the southeastern United States but were progressively extirpated and excluded from most areas. They survived in the least developed and most isolated part of their range, the mosaic of upland and wetland habitats of South Florida. Within this area, the distributions of both panthers and forest reflect a complex mix of land-, water-, and game-management decisions as well as numerous historical and ecological factors.

To a substantial degree, forested land can be viewed as a surrogate for the inaccessible or undisturbed areas that served as refugia in the years before panthers were protected from hunting. Therefore, it is not surprising that the distribution of panther telemetry locations shows a relationship to forest cover. The inability to recolonize viable habitat because of natural and manmade barriers and reduced fecundity caused by inbreeding helped to maintain this relationship, leading some observers to infer habitat preference from the association of panther habitation with forest cover. Recent monitoring data from areas with fragmented forest cover suggest that the relationship of panther distribution to forest cover is much more complex than 
previously hypothesized, which can be explained mainly by factors other than habitat.

Substantial portions of South Florida that are nonforested have been altered by humans in ways that have excluded panthers and their prey. Extensive areas were modified as part of the large-scale drainage and impoundment project that includes a $3200-\mathrm{km}^{2}$ system of intensively managed Water Conservation Areas (WCAs) bounded by canals and levees. The South Florida Water Management District uses these WCAs to provide flood control during the wet season and hydration during the dry season to the Everglades Agricultural Area (EAA). The EAA covers $2800 \mathrm{~km}^{2}$ south of Lake Okeechobee and is planted largely in a monoculture of sugar cane (Fernald and Purdum 1998). In addition, large areas of natural habitat have been replaced by improved open pastures, often planted in short Bahia grass, from which the type of vegetative cover used by panthers and their prey has been removed. These alterations and current land-use practices exclude panthers from large expanses of unforested landscape in South Florida.

Historically, panthers were extirpated in much of what is now BCNP by hunting and by loss of prey during the tick fever eradication program in the late 1930s and early 1940s, when 10,000 deer were killed in Collier County alone (Stone 1979, Alvarez 1993). However, panthers failed to recolonize these habitats in significant numbers even though the deer herd was supplemented, the panther population was protected from hunting, and public areas of low human disturbance were established. The geographic isolation of survivors, characteristic dispersal behaviors, and diminished reproductive fitness in the small population probably contributed to the restricted distribution of panthers. Roads have played a prominent role in shaping panther distribution. Panther home ranges, especially those of females, are often closely bounded by highways (see Fig. 9), which may have acted as barriers to movement and dispersal by preventing the recolonization of BCNP from the north and west. As a result, subpopulations became isolated and suffered from inbreeding depression, further decreasing their reproductive potential (Seal and Lacy 1989). The genetic restoration program was implemented to overcome these barriers to recovery and has led to the first observed population expansion since monitoring began.

The limiting effects of panther dispersal behavior on population expansion can be seen by examining natural dispersals of young Florida panthers from their natal ranges. For example, in the Bear Island Unit of BCNP, the activity range of Florida panther female \#19 (in red in Fig. 11), substantially overlaps the range of her mother \#11 (black), whereas the larger range of \#11's male offspring, \#29 (in blue), is noncontiguous. These patterns are typical of panthers in South Florida. Males disperse an average distance of $40 \mathrm{~km}$ from the natal range. As a result, the observed overlap of adult male ranges with their natal range is negligible, whereas those of naturally dispersing females (19812000) show an mean overlap of 53\%.

Fig. 11. Home range boundaries of a female Florida panther (\#11 in black) and her dispersed male (\#29 blue) and female (\#19 red) offspring.

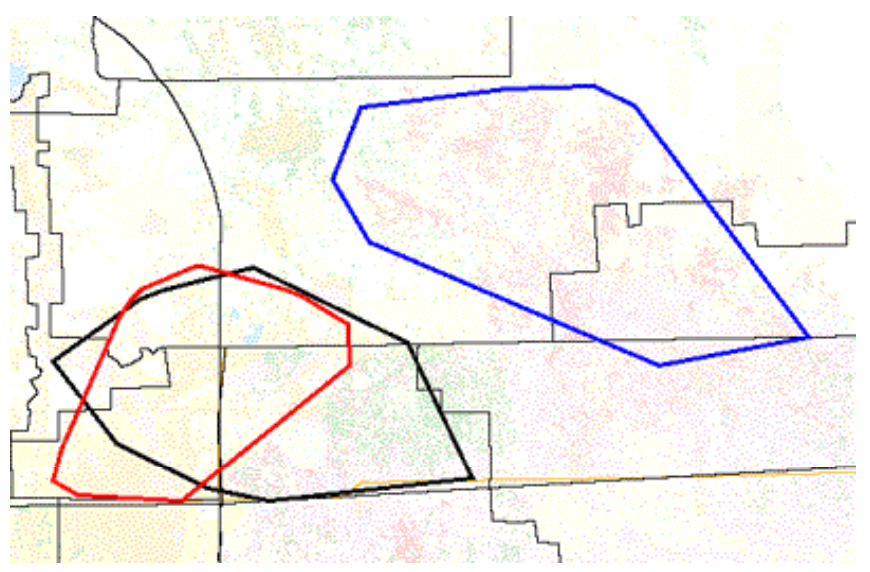

For some young females, no distinct "dispersal event" is observed. Instead, the mother and daughter move about together within a subarea of the natal range for a period of time, after which the mother moves to another part of her range, leaving the daughter established in a de facto adult range. Young males may disperse great distances and make excursions into unfamiliar territory. Because of limited female dispersion, however, they may find no potential mates in these outlying areas. In such cases, males typically make their way back to areas populated by females, sometimes retracing their path as they return.

These dispersal strategies contribute to reproductive fitness in several ways. Female offspring benefit from inheriting proven habitat with sufficient density of prey to support the nutritional needs of raising young. By staying close to home, females are also spared the hazards of dispersal through unfamiliar territory. Male offspring are likely to disperse to the vicinity of 
females to whom they are unrelated, reducing the potential for inbreeding and effecting gene exchange between breeding units throughout the range.

Fig. 12. Yearly panther activity ranges based on activity range polygon overlap (number of panthers-years of use) for A) adults in 1994, B) adults in 2000, C) juveniles during the period 1990-1994, and D) juveniles during the period 1996-2000. Color coding ranges from blue for low levels of use to magenta for high levels of use.

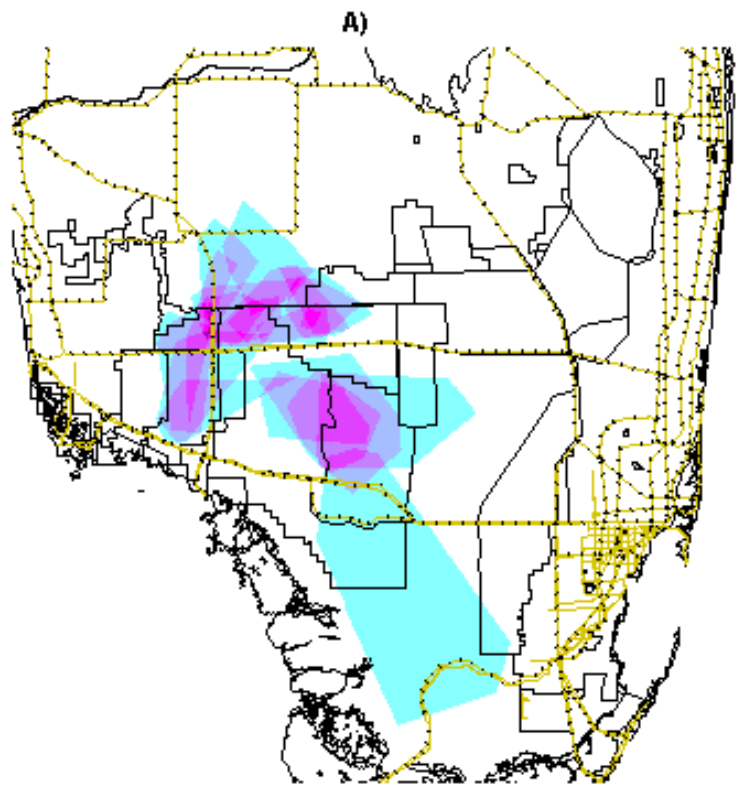

C)

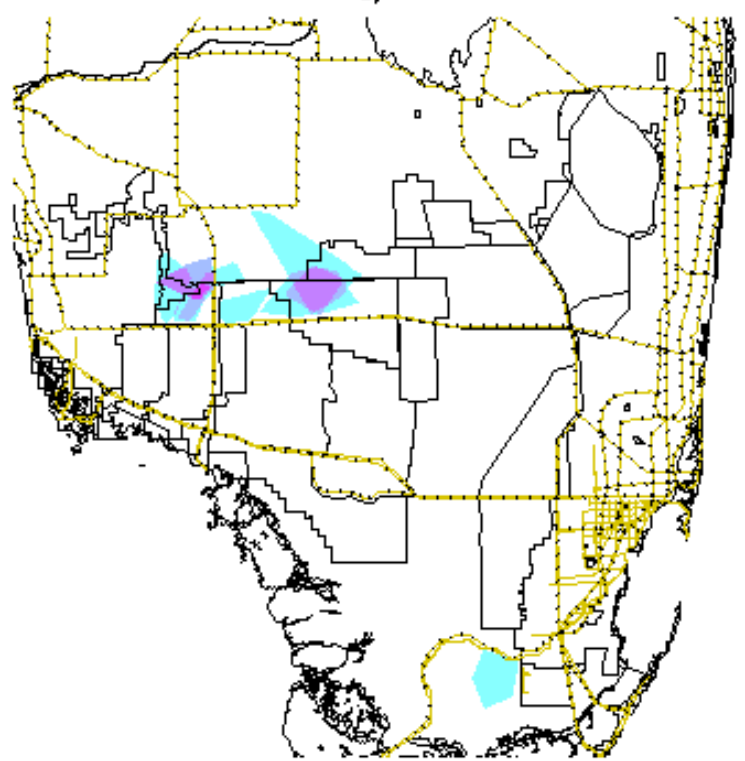

B)

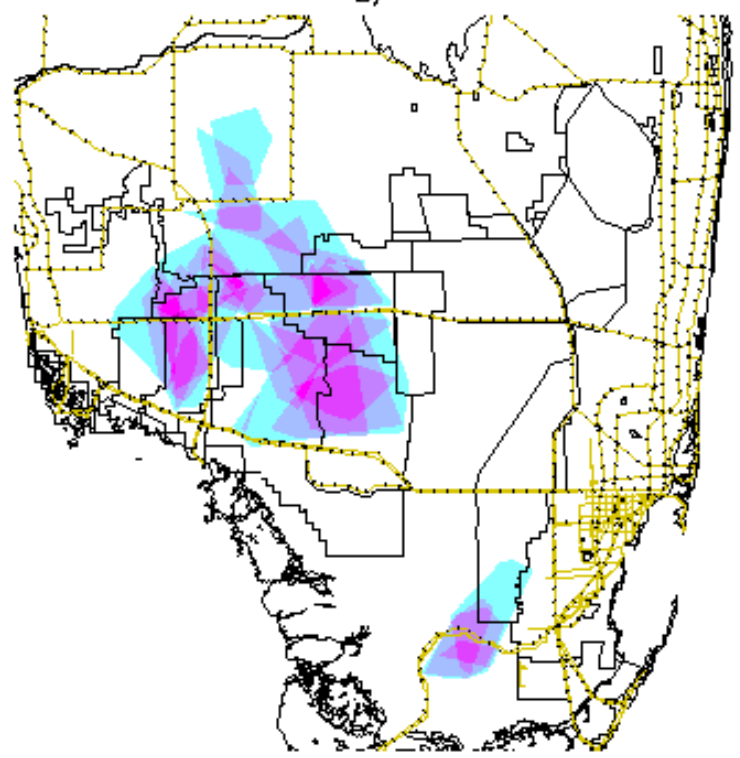

D)

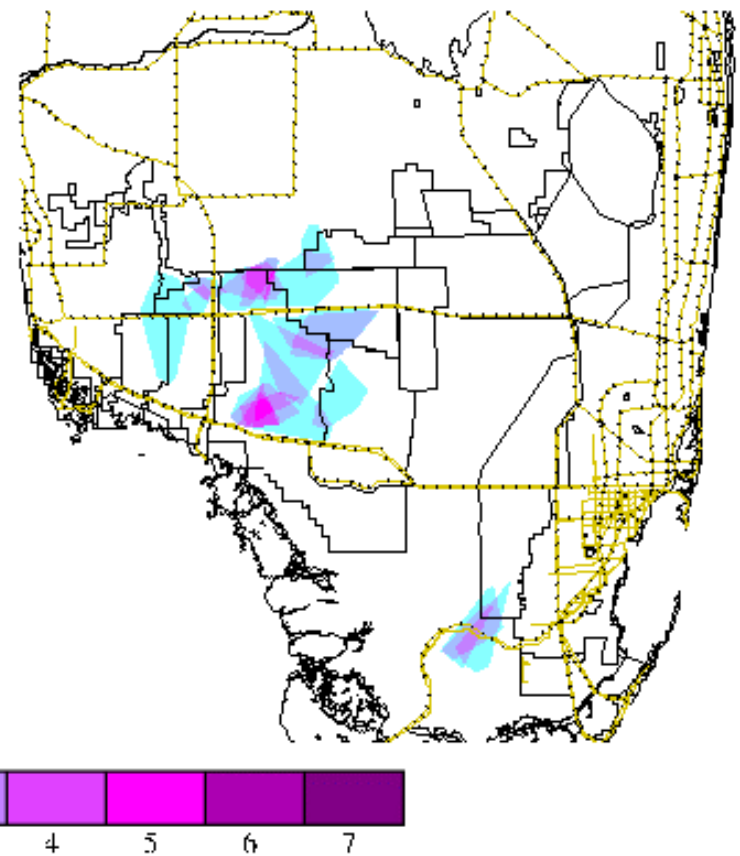

As a result of these dispersal strategies, disjunct or isolated habitats that fall vacant, such as southern BCNP or ENP, are unlikely to be recolonized in the absence of strong population expansion. Over the 20yr monitoring period, vacant areas of South Florida have been colonized either through gradual expansion of a subpopulation into an adjacent area (via overlapping female ranges) or by management intervention. The successful introduction of Texas females demonstrates that the low likelihood of recolonization of vacant areas can be addressed by translocating females into vacant habitats. Similar 
interventions could correct gender and genetic imbalances in isolated segments of the population.

In western populations of mountain lions, dispersal patterns are thought to be density dependent (Beier 1995). When western habitats reach carrying capacity, males disperse more widely and young females are more likely to establish ranges apart from the natal range. Similar trends for males have already been observed in South Florida as the population expands. Along with the dramatic increase in panther numbers in BCNP over the past few years has come the dispersal of three collared males across the Caloosahatchee River (Land et al. 1999; Shindle et al. 2000; McBride 2000, 2001), which was previously thought to be a barrier to expansion (Maehr 1997b).

Prior to the genetic introgression project (pre-1995), the public lands of South Florida were thought to be near carrying capacity (Maehr 1997a, 1997b). Nine panthers were being monitored in ENP and BCNP in early 1995, only four of whom occupied habitat south of I-75. As discussed above, studies of panther habitat use performed at that time, when all known panthers in the area were collared, attributed the scarcity of panthers in BCNP and ENP to the unsuitability of local habitat, specifically, to the absence of large stands of unfragmented forest (Maehr and Cox 1995, Maehr 1997a). However, these public areas are now occupied in much higher numbers by healthy, reproducing panthers. Currently, 47 panthers have been verified in BCNP and ENP, 25 of them collared (McBride 2001).

Comparisons of adult and juvenile activity ranges seen prior to 1995 with those seen after 1995 (Fig. 12A12D) illustrate why conclusions about habitat suitability made on the basis of preintrogression population dynamics were premature and should now be reevaluated. During the period 1990 to 1995, most Florida panthers were collared, whereas current monitoring covers only about half the verified population (McBride 2001). Factors other than habitat have clearly contributed to such a dramatic change in the population. Although data are not yet available for display, ranges in BCNP and ENP are reported to have expanded further during 2001 (Shindle et al. 2001; R. T. McBride, personal observation).

The relatively large panther home ranges seen in ENP and portions of BCNP prior to the genetic introgression program were regarded as confirmation of the primacy of forest in panther habitat quality
(Maehr 1997b). However, current home ranges in ENP and BCNP are comparable in size to those in more extensively forested areas. A likely factor contributing to the large home-range sizes of isolated panthers is their increased activity in search of potential mates. For example, the solitary home range of Chekika expanded to more than 340,000 ha in the early 1990s, when no females were available in ENP. His range returned to a more typical size of 40,000 ha after two Texas females were introduced into ENP.

It now seems clear that restricted pre-1995 panther distributions can be substantially explained by factors other than habitat suitability, including lowered female fecundity and kitten survival in an inbred population, historical extirpations, barriers to dispersal, and characteristic female dispersal patterns. The next few years should provide an opportunity to document the effects of density-dependent pressure on a growing panther population and allow for a more realistic appraisal of the relative importance of habitat components for panther survival and recovery. Careful monitoring of the population as it nears carrying capacity should reveal limiting conditions and the responses of panthers to these conditions, including changes in dispersal patterns, degree of home range overlap, causes of mortality, and kitten survival rates.

\section{Implications for panther habitat preservation and management}

The nature of panther habitat use is more than a theoretical issue. Questions about the importance of landscape components for sustaining viable panther populations have important practical implications for both management of public lands and conservation of panther habitat on private lands.

A significant portion of the public land in South Florida is dominated by wetland habitats with small, scattered patches of forest. Acceptance of the view that panthers require large tracts of unfragmented forest would minimize the responsibility of public land managers to contribute to panther recovery (Maehr 1997b). However, if such habitat were considered suitable, panthers living there would be managed as part of a larger metapopulation. Actions to correct gender and genetic imbalances, recolonize vacant habitats, enhance prey, and promote the connectivity of subareas would probably be undertaken. Decisions related to the Central Everglades Restoration Plan for hydrologic restoration would be closely evaluated for potential impacts on panthers. 
Prior to the genetic restoration program, when few panthers lived exclusively on the public domain, public lands in ENP and BCNP south of I-75 were characterized as being such poor panther habitat because of scarcity of forest resources that the panthers residing there were considered the "living dead" of the population (Maehr 1997b). These areas were described as population sinks unable to support reproduction and sustained only by dispersal from upland habitats to the northwest. In fact, dispersal into public lands from the northeast have been rare, because movement in this direction has been blocked by highways. These public lands are now centers of postintrogression panther expansion, supporting robust, healthy panthers (McBride 2000, 2001; Shindle et al. 2001). Approximately $40 \%$ of the South Florida panther population currently lives in ENP and BCNP south of I-75. These recent dynamics indicate that, in the past, the numbers of panthers in these areas were low because of factors other than unsuitability of habitat. In South Florida, the panther has demonstrated its ability to adapt to a wide variety of habitat configurations in which prey are available and human disturbance is minimal.

Regulatory land use decisions in South Florida are also driven by perceptions of the relative importance of various landscape components to panther survival. In this rapidly developing region, where numerous interests conflict with those of panthers, narrowly defined forest-centered characterizations of habitat suitability play an important role in land-use permitting reviews. Such characterizations are used to support the argument that no restrictions should be placed on the development of unforested land because only forested land is vital to panthers (A. Eller and K. Dryden, personal observation). Similarly, the view that panthers require large tracts of unfragmented forest limits the areas to which land use restrictions would apply, because few such tracts remain in South Florida.

Strategies for habitat protection that conserve only forested areas fail to consider well-established patterns of panther social structure, movement, hunting, reproduction, and dispersal, and will likely lead to the fragmentation of home ranges, the disruption of breeding units, and continued loss of panther habitat over time. Connectivity with adjacent areas will be permanently lost. Forest edge that no longer interfaces with viable prey habitat will cease to provide hunting opportunities. Marginal habitat important to transient subadult males will be further degraded. Such losses will jeopardize the survival of the current population as well as its ability to expand to other areas.

Because female panthers typically disperse only short distances from their natal ranges, private lands adjacent to occupied habitat hold the greatest potential for population expansion and should receive appropriate consideration in conservation and land use decisions. Small landscape patches isolated from the breeding range cannot support populations large enough to overcome the effects of inbreeding and demographic fluctuations that threaten the survival of small populations (Seal and Lacy 1989). Therefore, mitigation strategies that trade habitat within or adjacent to the occupied panther range for disjunct patches will likely result in a net loss of panther habitat.

Telemetry-based habitat selection studies do not capture the full spectrum of panther requirements or the flexibility with which panthers exploit their environment. Therefore, metrics derived from these analyses have limited usefulness for purposes of management and conservation, and their potential for misuse is great. In the zone of panther occupation or in areas of potential reintroduction/expansion, a large tract of forest with understory and prey is clearly suitable habitat for panthers. However, this does not imply that (1) all land that is not densely forested should be discounted as potential panther habitat or (2) unforested land within existing home ranges can be lost without jeopardy to panthers on the erroneous supposition that the forested portion is all that panthers use. These are issues of contention in South Florida land-use decision making, and it is on these points that science must weigh in.

The forest-centered view of habitat quality has mischaracterized more than 400,000 acres of public land in South Florida. This focus on one home-range component should be reevaluated before being applied to future habitat preservation and panther management decisions. We suggest a new paradigm that recognizes the adaptability of the panther and considers the ecological principles that underlie its survival in South Florida. Foremost among these is the need to maintain the integrity of the panther breeding range and the breeding units contained therein. This new focus requires a landscape-based perspective that expands the concern for forest fragmentation to include fragmentation of the habitat mosaic that supports panthers and their prey. Within the context of breeding units, the effects of fragmentation on productivity, 
connectivity, and other ecological attributes important to panther survival should be assessed, and appropriate and consistent management strategies should be developed.

Panthers are endangered in Florida for the same reasons that populations of large predators are declining all over the world. They require abudant prey, large individual home ranges, and a relatively undisturbed habitat area extensive enough to support a self-sustaining population (Clark et. al. 1996, Weber and Rabinowitz 1996). Essential to formulating a landscape-based panther habitat conservation strategy is understanding why panthers survived in South Florida as they vanished from the rest of their eastern range. The most salient features of the currently occupied range are its size, contiguity, and relative isolation from human disturbance. In terms of potential panther habitat, there is nothing of comparable extent and quality in the eastern United States. Within this range, panthers live in networks of large overlapping home ranges and breeding units that encompass the mosaic of habitats described above. An effective panther-conservation strategy will preserve this functionality in the occupied range and identify similar areas suitable for recolonization.

\section{CONCLUSIONS}

The results of our study, which was based on 21 years of telemetry data and field observations, strongly indicate that Puma concolor in Florida, as in other parts of its range, is a habitat generalist, adaptable to a wide range of habitats and habitat configurations. Our evaluation shows that, with the exception of coastal mangrove forests and open water, panthers in South Florida occupy all the natural habitat available to them. No simple rule can be derived to determine what is or is not "panther habitat." A more relevant concept is that of "habitat use," which describes the way in which a panther population exploits its occupied range.

A forest-centered view of panther habitat association emerged in the early to mid-1990s as an attempt to explain both habitat preferences within home ranges and the restricted panther distribution on the landscape. Published analyses of panther telemetry data at two scales, i.e., habit use within the home range and home range distribution within the overall study area, seemed to confirm the primacy of forests in panther habitat selection. However, these studies were based on two key untested hypotheses: (1) that daytime radiolocations were representative of 24-hr habitat use and (2) that the restricted geographical distribution of panthers was driven primarily by habitat suitability.

The results of our evaluation support neither of these hypotheses. The success of panther recolonization of areas considered unsuitable by forest-centered criteria has served as a decisive test of the hypothesis that these areas cannot support panther reproduction. We conclude that this view is based on an inappropriate use of telemetry data that represent a biased subsample of panther habitat use. We further conclude that the use of an aggregated land-cover classification such as "forest" has limited usefulness for understanding panther dynamics or making management and habitat protection decisions within the occupied panther range. Further fragmentation or degradation of any habitat component of an occupied home range diminishes its utility.

Field observations and literature on the species in other parts of its geographic range indicate that panthers are most active during the dusk-to-dawn period when they leave the protection of the day bed cover to hunt and otherwise travel within their home ranges. All available data indicate that panthers move freely within large home ranges, using and benefiting from the full spectrum of natural habitats available to them. The primary needs of panthers are an extensive area with a high degree of connectivity and minimal disturbance, the availability of large prey, and cover for denning and resting. We conclude that the mosaic of habitats in South Florida, not forest alone, fulfills these needs. Forest with understory may provide denning and resting sites, and forest edge provides hunting cover where forests interface with productive open areas used by prey. However, these vital components cannot be considered in isolation from the full spectrum of other requirements met within home ranges or from the habitat matrix in which they occur.

Biological processes that contribute to individual fitness, survival, and reproductive success drive panther habitat selection. No evidence has been presented that all the vital needs of panthers are met by daytime resting-site habitat or that the amount of forest within a home range substantially determines its size or quality. These views have persisted despite the availability of substantial evidence that panthers use a wide spectrum of habitats in addition to forests. Failure to examine assumptions and methods critically has led to a focus in panther conservation on resting 
site habitat to the exclusion of other requirements that impinge on survival and reproductive success.

We suggest a more ecologically consistent management and recovery paradigm based on the concept of a "viable breeding range" made up of overlapping "breeding units" composed of at least one resident male whose range encompasses the ranges of a number of breeding females. The panther population in South Florida is composed of a network of these units, which characterize panther social structure and satisfy reproductive requirements. The process of panther recovery involves the protection and nurturing of established breeding units and the expansion of the contiguous breeding range. Rather than focusing narrowly on preserving habitat for one home-range component, such as resting sites, habitat conservation strategies should be designed to preserve the integrity and functionality of existing breeding systems and ensure the prerequisites for their establishment in expansion zones and reintroduction sites.

Responses to this article can be read online at: http://www.consecol.org/vol6/issl/art18/responses/index.html.

\section{Acknowledgments:}

The work presented here has been supported by the ATLSS Project, with funding provided in significant part by the DOI's Critical Ecosystems Studies Initiative, through the Biological Resources Division of the U.S. Geological Survey, Florida Caribbean Science Center, under Cooperative Agreement \#1445-CA09-95-0094, Subagreement \#1 with the University of Tennessee. The statements, findings, conclusions, recommendations, and other data in this report are solely those of the authors and do not necessarily reflect the views of the U.S. Geological Survey. The computational facilities provided through the National Science Foundation (Award EIA9972889) to the Scalable Intracampus Research Grid (http://www.cs.utk.edu/sinrg/) at the University of Tennessee were instrumental in carrying out the research presented here. We thank Darrell Land and David Shindle with the Florida Fish and Wildlife Conservation Commission and Deborah Jansen of Big Cypress National Preserve for access to telemetry data sets collected over the period 1981-2000. We thank Don DeAngelis for helpful comments and suggestions during manuscript preparation.

\section{APPENDIX 1}

Table A1.1. Summary statistics for size (in hectares) of home ranges for monitored adult panthers (resident $>1.5 \mathrm{yr}$ ) in South Florida for the period 1981-2000. $N$ is the number of monitored panthers, and CV stands for the coefficient of variation.

\section{APPENDIX 2}

Table A2.1. Summary statistics for percent difference $(P D)$, number of telemetry locations, and percent forest cover by grid plot for all monitored panthers in South Florida for the period 1981-2000.

\begin{tabular}{lccccc}
\hline \multicolumn{7}{c}{ Summary statistics } \\
\hline & $N^{\dagger}$ & Mean & $\begin{array}{c}\text { Std. } \\
\text { error }\end{array}$ & Minimum & Maximum \\
\hline$P D$ & 39 & $3.11^{\dagger}$ & 0.97 & -14.72 & 30.87 \\
& 37 & $3.73^{\ddagger}$ & 0.88 & 0.28 & 30.87 \\
& 25 & $1.50^{\ddagger}$ & 0.75 & -14.72 & 8.02 \\
& 24 & $2.18^{\ddagger}$ & 0.33 & 0.46 & 8.02 \\
Log $P D$ & 37 & $0.80^{\ddagger}$ & 0.16 & -1.27 & 3.43 \\
& 24 & $0.57^{\ddagger}$ & 0.13 & -0.78 & 2.08 \\
Percent forest cover & 39 & 21.65 & 3.08 & 0.92 & 63.60
\end{tabular}




\begin{tabular}{|c|c|c|c|c|c|}
\hline & 37 & 22.71 & 3.15 & 0.92 & 63.60 \\
\hline & 25 & 27.24 & 3.91 & 1.23 & 63.60 \\
\hline & 24 & 28.32 & 3.91 & 1.65 & 63.60 \\
\hline \multirow[t]{4}{*}{ Number of locations } & 39 & 916.2 & 233.6 & 4 & 5644 \\
\hline & 37 & 956.4 & 244.6 & 4 & 5644 \\
\hline & 25 & 1407.9 & 326.7 & 97 & 5644 \\
\hline & 24 & 1455.7 & 337.0 & 97 & 5644 \\
\hline
\end{tabular}

'Number of plots in data set:

39 grid plots with $>0$ telemetry locations

37 grid plots with $>0$ telemetry locations and positive values of $P D$

25 grid plots with $>90$ telemetry locations

24 grid plots with $>90$ telemetry locations and positive values of $P D$

significantly different at $\mathrm{P}=0.05$.

Table A2.2. Correlations for percent difference $(P D)$, number of telemetry locations, and percent forest cover by grid plot for all monitored panthers in South Florida for the period 1981-2000.

\begin{tabular}{|c|c|c|c|c|c|}
\hline \multicolumn{6}{|c|}{ Correlations } \\
\hline & & \multicolumn{2}{|c|}{ Percent forest cover } & \multicolumn{2}{|c|}{ Number of locations } \\
\hline & $N^{\dagger}$ & $r$ & $\begin{array}{c}\text { Significance } \\
\text { level }\end{array}$ & $r$ & $\begin{array}{c}\text { Significance } \\
\text { level }\end{array}$ \\
\hline \multirow[t]{4}{*}{$P D$} & 39 & -0.29 & 0.077 & -0.20 & 0.213 \\
\hline & 37 & -0.47 & 0.003 & -0.30 & 0.075 \\
\hline & 25 & -0.01 & 0.968 & -0.08 & 0.692 \\
\hline & 24 & -0.63 & 0.001 & -0.51 & 0.012 \\
\hline \multirow[t]{2}{*}{$\log P D$} & 37 & -0.67 & $<0.0001$ & -0.49 & 0.002 \\
\hline & 24 & -0.70 & 0.0001 & -0.70 & 0.0001 \\
\hline \multirow[t]{4}{*}{ Number of locations } & 39 & 0.58 & 0.0001 & $\ldots$ & $\ldots$ \\
\hline & 37 & 0.57 & 0.0002 & $\ldots$ & $\ldots$ \\
\hline & 25 & 0.55 & 0.004 & $\ldots$ & $\ldots$ \\
\hline & 24 & 0.54 & 0.007 & $\ldots$ & $\ldots$ \\
\hline
\end{tabular}

'Number of plots in data set:

39 grid plots with $>0$ telemetry locations

37 grid plots with $>0$ telemetry locations and positive values of $P D$

25 grid plots with $>90$ telemetry locations

24 grid plots with $>90$ telemetry locations and positive values of $P D$

\section{LITERATURE CITED}

Ackerman, B. B., F. G. Lindzey, and T. P. Hemker. 1986. Predictive energetics model for cougars. Pages 333352 in S. D. Miller and D. D. Everett, editors. Cats of the world: biology, conservation and management. National Wildlife Federation, Washington, D.C., USA.

Alderton, D. 1993. Wild cats of the world. Facts on File, New York, New York, USA. 
Alvarez, K. 1993. Twilight of the panther: biology, bureaucracy and failure in an endangered species program. Myakka River Publishing, Sarasota, Florida, USA.

Anderson, A. E. 1983. A critical review of literature on puma (Felis concolor) . Colorado Division of Wildlife, Wildlife Research Section, Denver, Colorado, USA.

Bass, O. L., Jr. 1994. Ecology and population dynamics of the Florida panther in Everglades National Park. Pages 8297 in D. Jordan, editor. Proceedings of the Florida Panther Conference.(Fort Myers, Florida, USA). U.S. Fish and Wildlife Service, Gainesville, Florida, USA.

Beier, P. 1995. Dispersal of juvenile cougars in fragmented habitat. Journal of Wildlife Management 59:228-237.

Beier, P., D. Choate, and R. H. Barrett. 1995. Movement patterns of mountain lions during different behaviors. Journal of Mammalogy 76:1056-1070.

Belden, R. C., and B. W. Hagedorn. 1993. Feasibility of translocating panthers into northern Florida. Journal of Wildlife Management 57:388-397.

Belden, R. C., W. Frankenberger, R. T. McBride, and S. T. Schwikert. 1988. Panther habitat use in southern Florida. Journal of Wildlife Management 52:660-663.

Clark, T. W., P. C. Paquet, and A. Peyton Curlee. 1996. Large carnivore conservation in the Rocky Mountains of the United States and Canada. Conservation Biology 10:936939.

Comiskey, E. J., L. J. Gross, D. M. Fleming, M. A. Huston, O. L. Bass, Jr., H.-K. Luh, and Y. Wu. 1994. A spatially-explicit individual-based simulation model for Florida panther and white-tailed deer in the Everglades and Big Cypress landscapes. Pages 494-503 in D. Jordan, editor. Proceedings of the Florida Panther Conference. (Fort Myers, Florida, USA). U.S. Fish and Wildlife Service, Gainesville, Florida, USA.

Dalrymple, G. H., and O. L. Bass, Jr. 1996. The diet of the Florida panther in Everglades National Park. Bulletin of the Florida Museum of Natural History 39:173-194.

DeAngelis, D. L., L. J. Gross, M. A. Huston, W. F. Wolff, D. M. Fleming, E. J. Comiskey, and S. M. Sylvester. 1998. Landscape modeling for Everglades ecosystem restoration. Ecosystems 1:64-75.

Dees, C. S., J. D. Clark, and F. T. Van Manen. 2001. Florida panther habitat use in response to prescribed fire. Journal of Wildlife Management 65:141-147.

Dixon, K. R. 1982. Mountain lion. Pages 711-727 in J. A. Chapman and G. A. Feldhamer, editors. Wild mammals of North America: biology, management, and economics. The Johns Hopkins University Press, Baltimore, Maryland, USA.
Fernald, E. A., and E. D. Purdum, editors. 1998. Water resources atlas of Florida. Institute of Science and Public Affairs, Florida State University, Tallahassee, Florida, USA.

Fleming, M. 1994. Distribution, abundance, and demography of white-tailed deer in the Everglades. Pages 247-274 in D. Jordan, editor. Proceedings of the Florida Panther Conference. (Fort Myers, Florida, USA). U.S. Fish and Wildlife Service, Gainesville, Florida, USA.

Guggisberg, C. A. W. 1975. Puma, cougar. Pages 107-124 in C. A. W. Guggisberg. Wild cats of the world. Taplinger, New York, New York, USA.

Hemker, T. P., F. G. Lindzey, B. B. Ackerman, and A. J. Button. 1984. Population characteristics and movement patterns of cougars in southern Utah. Journal of Wildlife Management 48:1275-1284.

Hornocker, M. 1969. Winter territoriality in mountain lions. Journal of Wildlife Management 33:457-464.

Janis, M. W. 1999. The effects of recreational deer and hog hunting on the behavior of Florida panthers. Thesis. University of Tennessee, Knoxville, Tennessee, USA.

Kerkhoff, A. J., B. T. Milne, and D. S. Maehr. 2000. Toward a panther-centered view of the forests of South Florida. Conservation Ecology 4(1):1. [online] URL: http://www.consecol.org/vol4/iss1/art1.

Land, D. 1994. Panther use of the southern Florida landscape. Pages 278-284 in D. Jordan, editor. Proceedings of the Florida Panther Conference. (Fort Myers, Florida, USA). U.S. Fish and Wildlife Service, Gainesville, Florida, USA.

Land, D., and R. Lacy. 2000. Introgression level achieved through Florida panther genetic restoration. Endangered Species Update 17:100-105.

Land, D., D. Shindle, D. Singler, and S. Taylor. 1999. Florida Panther Genetic Restoration and Management: annual progress report, 1998-1999. Florida Fish and Wildlife Conservation Commission, Tallahassee, Florida, USA.

Loveless, C. M. 1959. The Everglades deer herd: life history and management. Technical Bulletin Number 6 . Florida Game and Fresh Water Fish Commission, Tallahassee, Florida, USA.

McBride, R. T. 2001. Current panther distribution, population trends, and habitat use: report of field work: fall 2000-winter 2001. Report to Florida Panther SubTeam of MERIT, U.S. Fish and Wildlife Service, South Florida Ecosystem Office, Vero Beach, Florida. Available online at http://www.panther.state.fl.us/news/pdf/rtm2001.pdf.

McBride, R. T. 2000. Current panther distribution and habitat use: a review of field notes, fall 1999-winter 2000. Report to Florida Panther SubTeam of MERIT, U.S. Fish 
and Wildlife Service, South Florida Ecosystem Office, Vero Beach, Florida. Available online at http://www.panther.state.fl.us/news/pdf/report.pdf.

McBride, R. T. 1994. Three decades of searching South Florida for panthers. Pages 42-45 in D. Jordan, editor. Proceedings of the Florida Panther Conference. (Fort Myers, Florida, USA). U.S. Fish and Wildlife Service.

McBride, R. T. 1976. The status and ecology of the mountain lion, Felis concolor stanleyana, of the TexasMexico border. Thesis. Sul Ross State University, Alpine, Texas, USA.

McCown, J. W. 1994. Big Cypress deer/panther relationships: deer herd health and reproduction. Pages 198204 in D. Jordan, editor. Proceedings of the Florida Panther Conference. (Fort Myers, Florida, USA). U.S. Fish and Wildlife Service, Gainesville, Florida, USA.

Maehr, D. S. 1997a. The comparative ecology of bobcat, black bear, and Florida panther in South Florida. Bulletin of the Florida Museum of Natural History 40:1-176.

Maehr, D. S. 1997b. The Florida panther: life and death of a vanishing carnivore. Island Press, Covelo, California, USA.

Maehr, D. S., and J. A. Cox. 1995. Landscape features and panthers in Florida. Conservation Biology 9:1008-1019.

Maehr, D. S., and R. P. Meegan. 2001. Corridors, landscape linkages, and conservation planning for the Florida panther: enhancing expansion potential for an endangered species; final report submitted to Lee County, Florida. University of Kentucky, Lexington, Kentucky, USA.

Maehr, D. S., D. Land, J. C. Roof, and J. W. McCown. 1990. Day beds, natal dens, and activity of Florida panthers. Proceedings of the Annual Conference of Southeast Fish and Wildlife Agencies 44:310-318.

Miller, K. E. 1993. Habitat use by white-tailed deer in the Everglades: tree islands in a seasonally flooded landscape. Thesis. University of Florida, Gainesville, Florida, USA.

Mohr, C. O. 1947. Table of equivalent populations of North American small mammals. American Midland Naturalist 37:223-249.

Pearlstine, L., S. E. Smith, and W. M. Kitchens. 2000. A gap analysis of Florida: final report. Florida Cooperative Fish and Wildlife Unit Technical Report Number 65. U.S. Geological Survey, Gainesville, Florida, USA.

Rettie, J. W., and P. D. McLoughlin. 1999. Overcoming radiotelemetry bias in habitat-selection studies. Canadian Journal of Zoology 77:1175-1184.

Resources Inventory Committee. 1998. Wildlife radiotelemetry: standards for components of British Columbia's biodiversity, Number 5. Version 2.0. Ministry of Environment, Lands and Parks. Available online at http://srmwww.gov.bc.ca/risc/pubs/tebiodiv/wildliferadio/in dex.htm.

Schortemeyer, J. L. 1994. Habitat management for panthers in South Florida. Pages 460-466 in D. Jordan, editor. Proceedings of the Florida Panther Conference. (Fort Myers, Florida, USA). U.S. Fish and Wildlife Service, Gainesville, Florida, USA.

Seal, U. S., editor. 1994. A plan for genetic restoration and management of the Florida panther. Florida Game and Freshwater Fish Commission, Tallhassee, Florida, USA.

Seal, U. S., and R. C. Lacy. 1989. Florida panther viability analysis and species survival plan; report to the U.S. Fish and Wildlife Service. IUCN/SSC Captive Breeding Specialist Group, Apple Valley, Minnesota, USA,.

Seidensticker, J. C., IV, M. G. Hornocker, W. V. Wiles and J. P. Messick. 1973. Mountain lion social organization in the Idaho Primitive Area. Wildlife Monographs 35:1-60.

Shaw, H. 1989. Soul among lions. Johnson books, Boulder, Colorado, USA.

Shindle, D., D. Land, K. Charlton, and R. McBride. 2000. Florida Panther Genetic Restoration and Management: annual progress report, 1999-2000. Florida Fish and Wildlife Conservation Commission, Tallahassee, Florida, USA.

Shindle, D., D. Land, M. Cunningham, and M. Lotz. 2001. Florida Panther Genetic Restoration and Management: annual progress report, 2000-2001. Florida Fish and Wildlife Conservation Commission, Tallahassee, Florida, USA.

Smith, T. R., and O. L. Bass, Jr. 1994. Landscape, whitetailed deer, and the distribution of Florida panthers in the Everglades. Pages 693-708 in S. Davis and J. Ogden, editors. Everglades: the ecosystem and its restoration. St. Lucie Press, Delray Beach, Florida, USA.

Stone, C. R. 1979. Forty years in the Everglades. Atlantic Publishing, Tabor City, North Carolina, USA.

Tinsley, J. B. 1987. The puma: legendary lion of the Americas. Texas Western Press, El Paso, Texas, USA.

Tinsley, J. B. 1970. The Florida panther. Great Outdoors Publishing, St. Petersburg, Florida, USA.

van Horne, B. 1983. Density as a misleading indicator of habitat quality. Journal of Wildlife Management 47:893901.

Weber, W., and A. Rabinowitz. 1996. A global perspective on large carnivore conservation. Conservation Biology 10:1046-1054. 
White, G. C., and R. A. Garrott. 1990. Analysis of wildlife radio-tracking data. Academic Press, San Diego, California, USA.

Young, S. P., and E. A. Goldman. 1964. The puma, mysterious American cat. Dover Publications, New York, New York, USA. 